\title{
Why cancer cells have a more hyperpolarised mitochondrial membrane potential and emergent prospects for therapy
}

\author{
Michael D. Forrest Ph.D. \\ Department of Computer Science, University of Warwick, Coventry, UK \\ E-Mail: mikeforrest@ hotmail.com
}

\begin{abstract}
Cancer cells have a more hyperpolarised mitochondrial membrane potential $\left(\Psi_{\mathrm{IM}}\right)$ than normal cells. $\Psi_{\mathrm{IM}}=\sim-220 \mathrm{mV}$ in cancer cells as compared to $\sim 140 \mathrm{mV}$ in normal cells. Until now it has not been known why. This paper explains this disparity, in a mathematical framework, and identifies molecular targets and operations unique to cancer cells. These are thence prospective cancer drug targets. BMS-199264 is proposed as an anti-cancer drug. It inhibits the reverse, proton-pumping mode of ATP synthase, which this paper identifies as crucial to cancer cells but not to healthy, normal adult cells. In the cancer cell model, the adenine nucleotide exchanger (ANT) is inversely orientated in the mitochondrial inner membrane as compared to normal cells. This predicts it to have a different drug interaction profile, which can be leveraged for cancer therapy. Uncouplers, which dissipate the proton motive force, are proposed as anti-cancer medicines e.g. 2,4-dinitrophenol.
\end{abstract}

\section{ARTICLE}

During aerobic respiration, the movement of electrons along the respiratory chain pumps protons across the inner mitochondrial membrane to build a proton motive force (pmf) [1-3]. The pmf is electrochemical, consisting of a hyperpolarised transmembrane voltage $\left(\Psi_{\mathrm{IM}}\right.$, negative inside) and a proton concentration gradient $(\delta \mathrm{pH}$, alkali inside). In vivo, with high concentrations of $\mathrm{Pi}, \delta \mathrm{pH}$ is minor as compared to $\Psi_{\mathrm{IM}}$ [4]. Protons move down this electrochemical gradient, through ATP synthase, to generate ATP. Eukaryote cells must maintain a hyperpolarized voltage across their inner mitochondrial membranes. If this hyperpolarisation dissipates, the voltage-sensitive permeability transition pore (PTP) will open and release pro-apoptotic agents (e.g. cytochrome c) into the cytoplasm and drive apoptotic cell death [5].

In a normal cell, $\Psi_{\mathrm{IM}}$ flickers between -108 and $-159 \mathrm{mV}$ : with a mean value of $-139 \mathrm{mV}[6$, 7]. Thermodynamically, the optimal $\Psi_{\mathrm{IM}}$ for maximal ATP production is between -130 to $140 \mathrm{mV}$, a rule that applies for all living organisms [7]. 10\% value alterations in $\Psi_{\mathrm{IM}}$, above 
or below its optimum, results in a 90\% decrease in ATP synthesis and a $~ 90 \%$ increase in harmful reactive oxygen species (ROS) [7].

Cancer cells have a more hyperpolarised $\Psi_{\text {IM }}$ than normal cells [8-17]. The more invasive and dangerous the cancer, the more hyperpolarised its $\Psi_{\mathrm{IM}}$ is observed to be [14-16]. The hyperpolarisation of $\Psi_{\mathrm{IM}}$ can be $>50 \%$ greater in cancer cells than normal cells [14] e.g. $\Psi_{\mathrm{IM}}$ $=\sim-210 \mathrm{mV}$ in Neu4145 cancer cells [18]. The $\Psi_{\mathrm{IM}}$ hyperpolarisation in cancer cells can even be double that of normal cells [19]. So, generally, the $\Psi_{\mathrm{IM}}$ of cancer cells is extremely suboptimal for ATP production. However, these cancer cells aren't using aerobic respiration and aren't using $\Psi_{\mathrm{IM}}$ in the same way as normal cells.

Aerobic respiration is $\mathrm{O}_{2}$ dependent and uses glycolysis, the Krebs cycle and oxidative phosphorylation (OXPHOS) to produce ATP [1-3]. Aerobic glycolysis is the sole use of glycolysis to produce ATP, even in the presence of $\mathrm{O}_{2}$. Cancer cells can use aerobic glycolysis (Warburg effect) some or all of the time [18-39]. I propose that when in this mode, they have a more hyperpolarised $\Psi_{\mathrm{IM}}$. Indeed, experimentally, when cancer cells are switched out of aerobic glycolysis, into aerobic respiration, their $\Psi_{\mathrm{IM}}$ is returned to that of normal cells [18-19].

The fact that there is a disparity in $\Psi_{\mathrm{IM}}$ between normal and cancer cells is well established and has already been leveraged in human drug trials [40-41]. Delocalized lipophilic cations (DLCs) can cross membranes and their positive charge means they are drawn to, and accumulate in, the mitochondrial matrix (negative inside, because of hyperpolarised $\Psi_{\mathrm{IM}}$ ). Cancer cells have a more hyperpolarised $\Psi_{\mathrm{IM}}$ and so DLCs are more attracted to, and better retained by, their mitochondria than that of normal cells [12]. Using the Nernst equation [14], if the $\Psi_{\mathrm{IM}}$ of a cancer cell is $60 \mathrm{mV}$ more hyperpolarised than that of a normal cell - which is within the range of observation [14, 18-19] - then a single charged DLC will accumulate 10 times more in the mitochondrial matrix of cancer cells than normal cells ( $\mathrm{T}=300 \mathrm{~K}$ ). DLCs with a double charge will accumulate 100 times more [42]. So, DLC poisons are more targeted to cancer cells and this means there are likely to be doses that can kill cancer cells, but leave normal cells unharmed. Different DLCs have been shown to accumulate in and selectively kill cancer cells, in vitro and in vivo [11, 43-47]. This affirms that cancer cells do have a more hyperpolarised $\Psi_{\mathrm{IM}}$, although no DLC has been successful in clinical trialling to date. For example, MKT-077 caused renal toxicity in Phase 1 trials [40-41].

It is not known why or how cancer cells have a more hyperpolarised $\Psi_{\mathrm{IM}}$. I provide a quantitative explanation, which identifies molecular targets and operations unique to cancer 
cells. These can be leveraged as cancer drug targets. To understand how $\Psi_{\text {IM }}$ generation differs in cancer cells, we must first explain it for normal cells.

\section{The biophysics of $\boldsymbol{\Psi}_{\mathrm{IM}}$ in normal cells [4, 48-50]}

Mitochondrial ATP synthase $\left(\mathrm{F}_{0} \mathrm{~F}_{1}-\mathrm{ATPase}\right)$ can synthesise or hydrolyse ATP. Protons can flow "downhill" through the ATPase, to generate ATP, or be pumped "uphill" by the ATPase, using ATP. The mitochondrial Adenine Nucleotide Transporter (ANT) can export $\mathrm{ATP}^{4-}$ for the import of $\mathrm{ADP}^{3-}$, or conduct the inverse. So, both ATPase and ANT catalyse reversible processes. Their directionality is governed by the mitochondrial membrane potential $\left(\Psi_{\mathrm{IM}}\right)$ in relation to their reversal potential, $\mathrm{E}_{\text {rev_ATPase }}$ and $\mathrm{E}_{\mathrm{rev} \_\mathrm{ANT}}$ respectively $(\mathrm{mV})$. Which are set by the concentrations of the participating reactants, as shown in Equations 1-11 [4, 50].

\section{[1] The ATPase:}

$$
E_{\text {rev_ATPase }}=-\left(\frac{316}{n}\right)-\left(\frac{2.3 \cdot R \cdot T}{F} / n\right) \cdot \log \left(\frac{\left[A T P^{4-}\right]_{i n} \cdot K_{W}}{\left[A D P^{3-}\right]_{i n} \cdot\left[P^{-}\right]_{\text {in }} \cdot K_{Q}}\right)-\frac{2.3 \cdot R \cdot T}{F} \cdot p H_{\text {out }}-p H_{\text {in }}
$$

$$
\left[P^{-}\right]_{\text {in }}=\left[P_{\text {total }}\right]_{\text {in }} /\left(1+10^{p H_{\text {in }}-p K_{a 2}}\right)
$$

Where in relates to inside the mitochondrial matrix, out relates to outside the matrix (mitochondrial intermembrane space and cytoplasm), $n$ is the $\mathrm{H}^{+}$/ATP coupling ratio of the ATPase, $R$ is the universal gas constant $\left(8.31 \mathrm{~J} \cdot \mathrm{mol}^{-1}\right), F$ is the Faraday constant $\left(9.64 * 10^{4} \mathrm{C} \cdot \mathrm{mol}^{-1}\right), T$ is temperature (K), $\mathrm{K}_{\mathrm{W}}$ is the affinity constant for ADP, $\mathrm{K}_{\mathrm{Q}}$ is the affinity constant for ATP, $\left[P^{-}\right]_{\text {in }}$ is the free phosphate concentration inside, $\left[P_{\text {total }}\right]_{\text {in }}$ is the total phosphate concentration inside, $p K_{a 2}=7.2$ for phosphoric acid $\left(\mathrm{H}_{3} \mathrm{PO}_{4}\right)$.

\section{[2] The ANT exchanger:}

$$
E_{\text {rev_ANT }}=\frac{2.3 \cdot R \cdot T}{F} \cdot \log \left(\frac{\left[A D P^{3-}\right]_{\text {out }} \cdot\left[A T P^{4-}\right]_{\text {in }}}{\left[A D P^{3-}\right]_{\text {in }} \cdot\left[A T P^{4-}\right]_{\text {out }}}\right)
$$

Note in Equations 1, 2 and 3: that the ATPase and ANT only (directly) share 2 common reactants: $\left[A T P^{4-}\right]_{\text {in }}$ and $\left[A D P^{3-}\right]_{\text {in }}$.

[3] The free ATP concentration inside $\left[A T P^{4-}\right]_{\text {in }}$ : 
$\left[A T P^{4-}\right]_{i n}=\frac{[L]_{i n} /\left(1+\left[M^{2+}\right]_{i n_{-} \text {free }} / K_{L}\right)}{1+10^{-p H_{\text {in }}} / K_{H}}$

$[L]_{i n}=\left[A T P^{4-}\right]_{i n}+\left[A T P-H^{3-}\right]_{i n}+\left[A T P-M g^{2-}\right]_{i n}+\left[A T P-H-M g^{-}\right]_{i n}$

$K_{L}$ is the dissociation constant for the reaction: $A T P-M^{2-} \longleftrightarrow K_{L} A T P^{4-}+M^{2+}$

$K_{H}$ is the dissociation constant for the reaction: $A T P-H^{3-} \underset{K_{H}}{\longleftrightarrow} A T P^{4-}+H^{+}$

[4] The free ADP concentration inside $\left[A D P^{3-}\right]_{i n}$ :

$\left[A D P^{3-}\right]_{i n}=\frac{[Y]_{i n} /\left(1+\left[M^{2+}\right]_{i n_{-} \text {free }} / K_{R}\right)}{1+10^{-p H_{\text {in }}} / K_{J}}$

$[Y]_{i n}=\left[A D P^{3-}\right]_{i n}+\left[A D P-H^{2-}\right]_{i n}+\left[A D P-M g^{-}\right]_{i n}+[A T P-H-M g]_{i n}$

$K_{R}$ is the dissociation constant for the reaction: $A D P-M g^{-} \longleftrightarrow K_{R} A D P^{3-}+M^{2+}$

$K_{J}$ is the dissociation constant for the reaction: $A D P-H^{2-} \underset{K_{J}}{\longleftrightarrow} A D P^{3-}+H^{+}$

[5] The free ADP and ATP concentrations outside - $\left[A D P^{3-}\right]_{\text {out }}$ and $\left[A T P^{4-}\right]_{\text {out }}$ respectively - are calculated by equations of the same form as those for inside; but are not shown here for brevity. The dissociation constants for $\left[A D P^{3-}\right]_{\text {out }}$ are $\mathrm{K}_{\mathrm{z}}$ and $\mathrm{K}_{\mathrm{x}}$. The dissociation constants for $\left[A T P^{4-}\right]_{\text {out }}$ are $\mathrm{K}_{\mathrm{o}}$ and $\mathrm{K}_{\mathrm{U}}$.

Figure 1 shows computational estimations of $\mathrm{E}_{\text {rev_ATPase }}$ and $\mathrm{E}_{\text {rev_ANT }}(\mathrm{mV})$ at different $[\mathrm{ATP}]_{\text {in }} /[\mathrm{ADP}]_{\text {in }}$ ratios $[4,48,50]$. This graph was made by computing Equations $1-11$ with parameters from [4]: $[\mathrm{ATP}]_{\text {out }}=1.2 \mathrm{mM},[\mathrm{ADP}]_{\text {out }}=10 \mu \mathrm{M},[\mathrm{P}]_{\text {in }}=0.01 \mathrm{M}, \mathrm{n}=3.7(2.7$ for the ATP synthase plus 1 for the electrogenic ATP ${ }^{4-} / \mathrm{ADP}^{3-}$ exchange of the ANT and the nonelectrogenic symport of phosphate and a proton by the phosphate carrier [51]), $\mathrm{pH}_{\text {in }}=$ $7.38, \mathrm{pH}_{\text {out }}=7.25, \mathrm{~T}=310 \mathrm{~K},\left[\mathrm{Mg}^{2+}\right]_{\text {in_free }}=0.5 \mathrm{mM}, \mathrm{K}_{\mathrm{W}}=10^{-3.198}, \mathrm{~K}_{\mathrm{Q}}=10^{-4.06}, \mathrm{~K}_{\mathrm{L}}=0.114$ $\mathrm{mM}, \mathrm{K}_{\mathrm{H}}=10^{-7.06} \mathrm{M}, \mathrm{K}_{\mathrm{R}}=0.906 \mathrm{mM}, \mathrm{K}_{\mathrm{J}}=10^{-6.8} \mathrm{M}, \mathrm{K}_{\mathrm{Z}}=0.906 \mathrm{mM}, \mathrm{K}_{\mathrm{X}}=10^{-6.8} \mathrm{M}, \mathrm{K}_{\mathrm{O}}=0.114$ $\mathrm{mM}, \mathrm{K}_{\mathrm{U}}=10^{-7.06} \mathrm{M}$. Traces were computed by Erev estimator software [4, 48, 50], which can be downloaded at: http://www.tinyurl.com/Erev-estimator.

During OXPHOS, protons are pumped by the complexes of the respiratory chain out of the mitochondrial matrix and into the mitochondrial intermembrane space. This hyperpolarises $\Psi_{\mathrm{IM}}$ and makes it more negative than $\mathrm{E}_{\text {rev_ATPase }}$ and $\mathrm{E}_{\text {rev_ANT }}$ (the green coloured "A-space" of Figure 1). With $\Psi_{\mathrm{IM}}$ hyperpolarised to $\mathrm{E}_{\text {rev_ATPase, }}$ ATPase works in its "forward" mode and synthesises ATP. With $\Psi_{\mathrm{IM}}$ hyperpolarised to $\mathrm{E}_{\text {rev_ANT, }}$ ANT works in its "forward" mode and 
exports mitochondrial matrix ATP for the import of cytoplasmic ADP. So, the mitochondrion produces and exports ATP. The "forward" operation of ANT and ATPase is a depolarising force to $\Psi_{\mathrm{IM}}$. $\mathrm{ATP}^{4-}$ export for $\mathrm{ADP}^{3-}$ import is depolarising and so are protons flowing "downhill" through ATPase. However, $\Psi_{\mathrm{IM}}$ doesn't depolarise because at the same time protons are being continually pumped "uphill" by the respiratory chain complexes, which is a hyperpolarising drive to $\Psi_{\mathrm{IM}}$. Actually, $\Psi_{\mathrm{IM}}$ doesn't remain constant during OXPHOS - but "flickers" (as much as >100 mV) [48-50] as these depolarising and hyperpolarising forces wrestle back and forth for a temporary net dominance.

If $\Psi_{\mathrm{IM}}$ is more positive (depolarised) than $\mathrm{E}_{\text {rev_ATPase }}$ and $\mathrm{E}_{\text {rev_ANT, }}$, they both work in their "reverse" mode (the grey coloured "C-space" of Figure 1). ATPase hydrolyses ATP and ANT imports cytoplasmic ATP for the exchange of mitochondrial matrix ADP. So, the mitochondrion imports and consumes ATP. In this state, ATPase pumps protons into the intermembrane space which hyperpolarises $\Psi_{\mathrm{IM}}$. In addition, ANT imports $\mathrm{ATP}^{4-}$ and exports $\mathrm{ADP}^{3-}$, so a negative charge is gained on the matrix side which hyperpolarises $\Psi_{\mathrm{IM}}$.

During OXPHOS, $\Psi_{\mathrm{IM}}$ is more negative than $\mathrm{E}_{\text {rev_ATPase }}$ and $\mathrm{E}_{\text {rev_ANT. }}$ If aerobic respiration is switched off, for example if the cell switches into aerobic glycolysis, then there will no longer be the hyperpolarising offset to the depolarising, "forward" action of ANT and ATPase: $\Psi_{\mathrm{IM}}$ will depolarise. $\mathrm{E}_{\text {rev_ATPase }}$ is more negative than $\mathrm{E}_{\text {rev_ANT }}$ and so $\Psi_{\mathrm{IM}}$ will depolarise past this reversal potential first. In this case, ATPase will switch into its "reverse" mode and ANT will remain in its "forward" mode (the orange coloured "B-space" of Figure 1). So, the ANT action will remain depolarising but the ATPase action will switch to being hyperpolarising - pumping protons out rather passing protons in. However, this reverse ATPase action requires ATP and with ANT pumping ATP out, there is little to be had. Furthermore, near the reversal potential of ATPase there is little driving force for an ATPase action. Hence, depolarising forces dominate and $\Psi_{\mathrm{IM}}$ depolarises further. When $\Psi_{\mathrm{IM}}$ is equal to E E rev_ANT $_{\text {ANen }}$ ANT does no "forward" or "reverse" ATP/ADP exchange and its effect on $\Psi_{\mathrm{IM}}$ is lost. At this point: With no ATP coming into the matrix, ATPase can no longer hydrolyse ATP to pump protons and its hyperpolarising action is also lost. In the absence of these forces, ensuing proton leak will depolarise the membrane potential. This will then make $\Psi_{\text {IM }}$ more depolarised than $\mathrm{E}_{\text {rev_ANT }}$ and permit ANT to conduct a hyperpolarising exchange of ATP/ADP. The more depolarised it is past $\mathrm{E}_{\text {rev_ANT, the more drive there is for this }}$ hyperpolarising exchange and the more that will occur. The resultant ATP entry will permit ATPase to conduct a hyperpolarising pumping of protons. So, there are hyperpolarising forces, conducted by ATPase and ANT, that come into play to prevent further depolarisation past $\mathrm{E}_{\text {rev_ANT. They cannot hyperpolarise }} \Psi_{\text {IM }}$ to be more negative than $\mathrm{E}_{\text {rev_ANT }}$ because these forces are largely lost at this point, but they can prevent further depolarisation past this point. The result is that $\Psi_{\mathrm{IM}}$ will oscillate around $\mathrm{E}_{\text {rev_ANT. }}$ So, at the loss aerobic respiration $\Psi_{\mathrm{IM}}$ will converge to $\mathrm{E}_{\text {rev_ANT. }}$ Hence, at the loss of aerobic respiration there is a "safety net" of 
mechanisms to prevent the collapse of $\Psi_{\mathrm{IM}}$ and the mass consumption of cytoplasmic ATP through mitochondrial proton pumping by ATPase.

At certain mitochondrial matrix $[\mathrm{ATP}]_{\text {in }} /[\mathrm{ADP}]_{\text {in }}$ ratios, it is possible for ATPase to be in "forward" operation and ANT to be in "reverse" operation (the whine coloured "D-space" of Figure 1). The former is depolarising, the latter hyperpolarising. However, it may be unlikely for mitochondria to have such a hyperpolarised $\Psi_{\mathrm{IM}}$ and a low matrix $[\mathrm{ATP}]_{\mathrm{in}} /[\mathrm{ADP}]_{\text {in }}$ ratio. So, it may be that this part of the graph has no biological representation and can be discounted $[4,50]$. The $\Psi_{\mathrm{IM}}$ in the "D-space" prompts ATPase to create ATP and ANT to import ATP. The ensuing rise in the $[\mathrm{ATP}]_{\text {in }} /[\mathrm{ADP}]_{\text {in }}$ ratio would push the system out of the "D- space" and into another area of the graph (Figure 1).

If proton pumping by the respiratory chain is stopped, but the Krebs cycle still persists, $\Psi_{\mathrm{IM}}$ will depolarise past $\mathrm{E}_{\text {rev_ATP }}$ but not all the way to $\mathrm{E}_{\text {rev_ANT. }}$. The Krebs cycle can produce ATP (or GTP) in its succinyl CoA to succinate step. Once $\Psi_{\text {IM }}$ is less negative than $E_{\text {rev_ATP, }}$ the ATP produced by the Krebs cycle may support the "reverse" ATP hydrolysing, proton pumping, hyperpolarising action of ATPase [4, 48-50]. This action will "hold" $\Psi_{\mathrm{IM}}$ in this

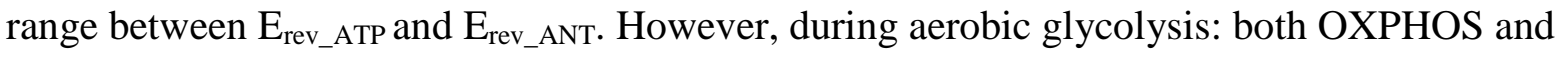
the Krebs cycle are shunted. So, this situation will not apply in this case. As aforementioned, $\Psi_{\mathrm{IM}}$ should converge upon and oscillate around $\mathrm{E}_{\text {rev_ANT. }}$.

IF-1 is a physiological protein, expressed by some tissues of some organisms, that inhibits the consumption of ATP by the $\mathrm{F}_{0} \mathrm{~F}_{1}$-ATPase [4]. So, it prevents the "reversal" of the ATPase

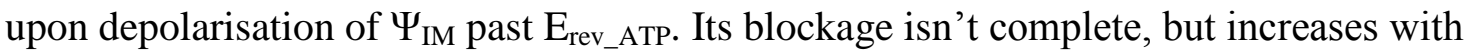
matrix [ATP], decreased matrix $\mathrm{pH}$ (acidification) and dissipated $\Psi_{\mathrm{IM}}$. With $\mathrm{F}_{0} \mathrm{~F}_{1}$-ATPases unable to "reverse", to confer a hyperpolarising pump of protons, they offer little resistance to an external, imposed depolarisation. So, this imposed depolarisation can converge relatively unopposed to $E_{\text {rev_ANT. }}$. Depolarisation past this point switches the ANT into producing a hyperpolarising exchange and this tries to "hold" $\Psi_{\text {IM }}$ at $E_{\text {rev_ANT, as described earlier. The }}$ result is that $\Psi_{\mathrm{IM}}$ will oscillate around $\mathrm{E}_{\text {rev_ANT. }}$ Unless the imposed depolarisation is strong enough to overcome this resistance, in which case the continued depolarisation will eventually open the voltage-dependent PTP and apoptosis is then all but assured.

\section{Why cancer cells have a more hyperpolarised $\Psi_{I M}$ is mysterious}

As aforementioned, I suggest that cancer cells have a more hyperpolarised $\Psi_{\mathrm{IM}}$ when they are utilising aerobic glycolysis. I suggest that this mode is a function of cancer proliferation and so the more aggressive and dangerous the cancer, the more time they spend in this operating 
state. During aerobic glycolysis, the Krebs cycle and OXPHOS are shunted and aren't used. By the reasoning of the previous section, $\Psi_{\mathrm{IM}}$ should thus converge upon - and oscillate around - $\mathrm{E}_{\text {rev_ANT. }}$. However, there is a problem. Refer to Figure 1 and note that $\mathrm{E}_{\text {rev_ANT }}$ is in a range around $\sim-120 \mathrm{mV}\left(-115 \mathrm{mV}\right.$ at matrix $[\mathrm{ATP}]_{\text {in }} /[\mathrm{ADP}]_{\text {in }}$ ratio $\left.=1.5\right)$. But the $\Psi_{\mathrm{IM}}$ of cancer cells is much more hyperpolarised: e.g. the $\Psi_{\mathrm{IM}}$ of Neu4145 cancer cells is $\sim-210 \mathrm{mV}$ [18].

\section{Cancer cells use a different ANT isoform}

The ANT referred to thus far in this manuscript is the ANT1 isoform. There are 4 human ANT isoforms (gene names in brackets): ANT1 (SLC25A4), ANT2 (SLC25A5), ANT3 (SLC25A6) and ANT4 (SLC25A31) [52]. They have 90\% homology, except ANT4 which has $\sim 70 \%$ homology to the others. A comparative study in yeast with the heterologous expression of ANT1, ANT2 and ANT3 (underneath the same promotor region) showed them all to have similar adenine nucleotide exchange characteristics [52]. ANT1 is expressed in differentiated adult cells. ANT2 is expressed in rapidly proliferating cells (embryonic stem (ES) cells, cancer cells). ANT3 is expressed at a low level ubiquitously. ANT4 is highly expressed in male gametes.

In differentiated adult cells, ANT1 is expressed highly and ANT2 expression is minimal [53]. I surmise that as a differentiated cell turns cancerous, and as it switches from aerobic respiration to aerobic glycolysis, it downregulates ANT1 and upregulates ANT2 expression. Indeed, in the majority of cancer cell lines, ANT1 expression is very low, whereas the expression of ANT2 is very high [53]. ANT3 expression is low across the board.

ANT1 and ANT3 are associated with aerobic respiration. They export the ATP produced by OXPHOS from the mitochondria into the cytosol, while importing ADP [54]. ANT2, by contrast, is associated with aerobic glycolysis [54]. When a cell is rapidly proliferating (e.g. cancerous) it switches off OXPHOS and ANT2 may import glycolytically produced ATP into mitochondria, while exporting ADP [54]. "Reverse" ATP synthase action hydrolyses this ATP to pump protons and maintain $\Psi_{\mathrm{IM}}$ and so prevent apoptosis [54]. ANT2 expression is a marker for rapid proliferation and/or cancer. Hence, specific inhibition of ANT2 is a prospective anti-cancer strategy.

\section{But ANT2 may not import ATP into mitochondria}

ANT2 import of ATP into mitochondria [54] is a hypothesis, although it is stated as an established fact in some of the literature, and there is a problem with this account [55-56]. 
Inhibition of OXPHOS alone (e.g. using myxothiazol, a Complex III respiratory inhibitor) cannot collapse the $\Psi_{\mathrm{IM}}$ of a cell using aerobic respiration. In addition, ATP synthase must be inhibited (e.g. using oligomycin) or ANT must be inhibited (e.g. using carboxyatractyloside or bongkrekic acid). Inhibiting ATP synthase or ANT inhibits the "reverse" action of ATP synthase, which can maintain $\Psi_{\text {IM }}$ in the absence of OXPHOS. ANT inhibition services this requirement by cutting off ATP delivery to ATP synthase. However, this is all the case for cells using aerobic respiration. It is not the case for cancer cells. In A549 human lung cancer cells, myxothiazol slightly decreases $\Psi_{\mathrm{IM}}$ and subsequent oligomycin collapses $\Psi_{\mathrm{IM}}$. However, carboxyatractyloside and bongkrekic acid fail to collapse $\Psi_{\mathrm{IM}}$. Nonetheless, subsequent oligomycin does lead to full depolarization. Similarly, 2-deoxyglucose, a glycolytic inhibitor, can collapse $\Psi_{\mathrm{IM}}$. These results show that the cancer cells are using mitochondrial ATP synthase to hydrolyse glycolytic ATP, to maintain $\Psi_{\mathrm{IM}}$. But that in cancer cells, entry of glycolytic ATP into mitochondria can occur by a pathway other than ANT [55]. This pathway is unknown. What could it be?

It could be through the electroneutral ATP-Mg/Pi carrier (APC) [55]. APC exchanges ATP $\left(\mathrm{Mg}_{-} \mathrm{ATP}^{2-}\right)$ for Pi (HPO4${ }^{2-}$ ) [57-58]. APC can alternatively exchange ADP (HADP ${ }^{2-}$ ) for Pi, if $\mathrm{Mg}^{2+}$ is absent. So, it could perform some "fudged" electroneutral ATP-ADP exchange.

Some intracellular parasites express ATP transporters on their plasma membrane when inside a host cell, to steal ATP from the host's cytoplasmic pool. There is a diversity of such parasites - e.g. chlamydia and rickettsiae bacteria [59-61], Lawsonia intracellularis [62] and the eukaryote: Encephalitozoon cuniculi [63]. PamNTT1, the ATP/ADP transporter from the amoeba symbiont Protochlamydia amoebophila (a chlamydia-related bacterium) [59] has an electroneutral action independent of the membrane potential. It exchanges [ATP ${ }^{4-}$ in for $\left[\mathrm{ADP}^{3-}\right.$ and $\left.\mathrm{Pi}^{-}\right]$out $[63]$. So, it is very distinct from ANT. Furthermore, it likely has 11-12 transmembrane domains; which is a significant difference from the 6 transmembrane helices of ANT and other members of the mitochondrial carrier family (MCF). I used BLAST [64] at http://blast.ncbi.nlm.nih.gov, with its default search parameters for "somewhat similar sequences" (blastn algorithm), to search the human genome for a PamNTT1 (NCBI accession number: AJ582021) homologue. With the idea that maybe such a homologue could be how rapidly proliferating/cancer cells import ATP into their mitochondria. However, none was found (data not shown). I then used BLAST again, with the same search parameters, to search the human genome for homologues of the ATP/ADP transporters from the eukaryote $E$. cuniculi [65]: EcNNT1-4 (GenBank accession numbers: EU040266-EU040270). However, none was found (data not shown).

Members of the mitochondrial carrier family (MCF) have a tripartite structure. That consists of three homologous sequence repeats of about 100 amino acid residues. Which each have a 
signature motif: P-X-[D/E]-X-X-[R/K] [66] (Prosite: PS50920). ANT and APC are members. The human genome likely encodes 48 different mitochondrial carriers [66]. A sizable proportion of these have not yet had their function assigned. It could be that one or more of these "orphan" transports facilitate ATP entry into mitochondria.

\section{ANT2 is essential to cancer cells; ANT1 and ANT3 kill cancer cells}

It might still be that ANT2 transports glycolytic ATP into mitochondria in cancer cells, but it isn't the only pathway for this. There may be a redundancy in this cancer system. Or ANT2 may have some other role. ANT2 does seem crucial to cancer cells.

I propose that cancer cell metabolism is similar to that of embryonic stem (ES) cells. Indeed, they share genetic expression fingerprints [67-68] and ES cells have a hyperpolarised $\Psi_{\mathrm{IM}}$ also [69]. They both employ aerobic glycolysis some or all of the time [18-39, 70], are immortal (divide forever without limit) [71-72] (as a function of using aerobic glycolysis [73]), respond to ROS damage by apoptosis rather than repair [19, 74] and can proliferate rapidly. So, with caution, we can learn more about cancer from ES cells and vice versa. In mice, ANT2 deficiency is embryonically lethal [75]. ANT2 is crucial to ES cells and we extrapolate from this to suggest that it is crucial to cancer cells. Indeed, ANT2 knockdown (RNA interference, shRNA) represses cancer proliferation and induces apoptotic death to cancer cells in vitro and in vivo [76]. Although others have reported ANT2 knockdown to have no such effect [77]; but this earlier, alternative report can be considered an inferior study because it used siRNA rather than shRNA; shRNA produces a more complete, robust, long lasting, long term knockdown [76].

In cancer cells, whereas ANT2 is anti-apoptotic [76], ANT1 is pro-apoptotic [78]. Overexpression of ANT1 induces apoptosis in cultured cancer cells by collapsing $\Psi_{\mathrm{IM}}$ and opening the voltage-dependent PTP [78]. Indeed, ANT1 transfection significantly suppresses tumor growth in vivo [78]. ANT3 is pro-apoptotic also [79]. Interestingly, over-expression of ANT1 is lethal to embryo cells [80], like it is to cancer cells.

\section{I predict that ANT2 is inserted in the inner mitochondrial membrane in the opposite orientation to ANT1 and ANT3}

I suggest that ANT2 does import ATP into mitochondria in cancer cells (and ES cells). I predict that ANT2 is orientated in the inner mitochondrial membrane in the opposite orientation than ANT1 and ANT3 (Figure 2). Furthermore, that this makes ANT2 resistant to inhibition by carboxyatractyloside (CAT) and bongkrekic acid (BKA), which are both 
inhibitors of ANT. This accounts for why these drugs cannot block ATP entry into the mitochondria of cancer cells, as mentioned earlier and described in [55-56].

BKA can be lipid soluble and can cross the inner mitochondrial membrane. CAT isn't and can't [81]. BKA crosses membranes as the electroneutral $\mathrm{BKAH}_{3}$. But it is its anionic form, $\mathrm{BKA}^{3-}$, which inhibits ANT [81]. CAT binds the intermembranous ("cytoplasmic") side of ANT. BKA binds the matrix side of ANT [81]. If ANT2 is inserted in the inner mitochondrial membrane in the opposite orientation than ANT1/ANT3 - if its " $\mathrm{m}$-side" is instead facing the cytoplasm (intermembranous space) and its "c-side" is instead facing the mitochondrial matrix - I anticipate that it will be resistant to inhibition by CAT or BKA. CAT won't be able to cross the inner mitochondrial membrane to access its binding site on the "c-side" of ANT, which is now in the mitochondrial matrix. BKA will be able to access its binding site on the "m-side" of ANT. But now this site is located in the acidic, proton rich environment of the intermembrane space. So, here, $\mathrm{BKA}^{3-}$ will quickly pick up protons and be converted to $\mathrm{BKAH}_{3}$. This form cannot inhibit ANT.

If ANT2 is orientated oppositely to ANT1/ANT3, it could confer it very different adenine nucleotide exchange kinetics; which are more suitable for cancer cells. Indeed, it may favour the import, rather than the export, of ATP. Without this re-interpretation, it is hard to see why ANT2 is so vital to cancer cells [76], and ANT1 and 3 so harmful [78-79], while they all have high sequence homology ( $90 \%)$. And similar adenine nucleotide transport capabilities when expressed in a heterologous yeast system $[52,82]$. I surmise that this heterologous system doesn't have the infrastructure to orientate ANT2 oppositely. So, ANT1, ANT2 and ANT3 are all orientated in the same way and, in this scenario, they do all have similar exchange characteristics. A further distinction is that an opposite orientation of ANT2 may make it less predisposed to joining in to make the permeability transition pore (PTP) in apoptotic scenarios (ANT can be a PTP component [83]).

An opposite orientation of ANT2 opens prospects for selective drugs. A drug that binds the "m-side" of ANT molecules, but that can't cross the inner mitochondrial membrane, may inhibit ANT2 (which has its "m-side" facing the cytoplasm) but not ANT 1 or 3 (which have their "m-side" in the mitochondrial matrix). So, this would be a selective anti-cancer drug. Alternatively, a drug (lipid or non-lipid soluble) that only binds the "m-side" of ANT in an acidic environment might selectively inhibit ANT2. It has its "m-side" in the acidic intermembranous space (IMS) rather than the alkali mitochondrial matrix. A delocalised lipophilic cation (DLC), that binds the "c-side" of ANT, would be preferentially located to the mitochondrial matrix by $\Psi_{\mathrm{IM}}$ where it could inhibit ANT2 and not ANT1/3. Alternatively, a drug that binds the "c-side" of ANT, tethered to a lipophilic cation to convey it passage through the inner mitochondrial membrane, and a positive charge(s) for targeting to the 
mitochondrial matrix, could inhibit ANT2 and not ANT1/3. A lipophilic anion (or a molecule tethered to one), that binds the "m-side" of ANT, would be preferentially located to the mitochondrial IMS by $\Psi_{\text {IM }}$ where it could inhibit ANT2 and not ANT1/3. Antibodies against the "m-side" or "c-side" of ANT may yield novel inhibitors. That could then be used in cancer therapy, to leverage the orientation disparity between ANT2 in cancer cells and ANT1/3 in normal cells. We have an ANT crystal structure [84]. The "m-side" and "c-side" of ANT are now conceivable cancer drug targets and should be targeted via in silico virtual screening, structure based drug design and high-throughput in vitro screening e.g. using chip technologies [85].

\section{The $E_{\text {rev_ANT }}$ of ANT1 and ANT3 is dangerous for cancer cells and this is why they downregulate them}

ANT3 is pro-apoptotic to cancer cells [79], ANT1 also [78]. Over-expression of ANT1 induces apoptosis in cultured cancer cells by collapsing $\Psi_{\mathrm{IM}}$ and opening the voltagedependent PTP [78]. For normal adult cells, we previously discussed how the $\mathrm{E}_{\text {rev_ANT }}$ of ANT1 protects $\Psi_{\mathrm{IM}}$ from depolarising to a voltage that opens the PTP and causes apoptosis. But here, in cancer cells, we see that ANT1 is pro-apoptotic [78] rather than anti-apoptotic as it is in normal cells $[4,48-50]$. I suggest that this is because the $\mathrm{E}_{\text {rev_ANT }}$ of ANT1 is more depolarised in cancer cells. If $\Psi_{\mathrm{IM}}$ converges to, and is held at this new $\mathrm{E}_{\text {rev_ANT }}$ potential, far from being protective - this takes $\Psi_{\mathrm{IM}}$ to a depolarised potential that opens the PTP and brings apoptosis. It is for this reason that cancer cells heavily downregulate the expression of ANT1 (and ANT3); such that it has a minimal effect on cancer metabolism unless it is upregulated by an artificial/experimental/therapeutic intervention. Why is the $\mathrm{E}_{\text {rev_ANT }}$ of ANT1 (and ANT3) more depolarised in cancer cells?

A high cytosolic ATP/ADP ratio inhibits glycolysis, through allosteric feedback of ATP on key glycolytic enzymes [1]. In aerobic respiration, much of this ATP will come from mitochondrial export. During aerobic glycolysis, ATP is imported into, rather than massexported out of, mitochondria and the ATP/ADP ratio is much lower in the cytoplasm [55]. A low cytoplasmic ATP/ADP ratio favours a high glycolytic rate, which is needed for rapidly proliferating cells. Indeed, one of the postulated reasons as to why rapidly proliferating cells favour aerobic glycolysis (with its higher glycolytic rate) some or all of the time is because glycolytic intermediates are needed in large quantities for macromolecular biosynthesis [8687]. A lower cytosolic ATP/ADP ratio shifts the E Erev_ANT of ANT1 (and ANT3) to more depolarised potentials. Figure 3(B) shows the shift in $\mathrm{E}_{\text {rev_ANT }}$ when cytoplasmic $[\mathrm{ATP}]$ is reduced fivefold from 1.2 to $0.24 \mathrm{mM}$ and cytoplasmic [ADP] is increased fivefold from 10 to $50 \mu \mathrm{M}$ (so the cytoplasmic ATP/ADP ratio decreases 25-fold). The midpoint on the $\mathrm{E}_{\text {rev_ANT }}$ curve, taken where the mitochondrial matrix ATP/ADP ratio on the $y$-axis $=1.5$, shifts from -115 to $-30 \mathrm{mV}$. Incidentally, these changes do not alter the $\mathrm{E}_{\text {rev_ATP }}$ curve. 
If there is a lower cytosolic ATP/ADP ratio we might surmise that there is a higher mitochondrial matrix ATP/ADP ratio. In Equations 1-11, a higher matrix ATP/ADP ratio shifts the $\mathrm{E}_{\text {rev_ANT }}$ of ANT1 (and ANT3) to more depolarised potentials. Looking at the y-axis of Figure 3(B), if the ATP/ADP matrix ratio=1.5: $\mathrm{E}_{\text {rev_ANT }}$ is $-30 \mathrm{mV}$. If the matrix ratio=3, $\mathrm{E}_{\text {rev_ANT }}$ is $-12 \mathrm{mV}$. Increasing the matrix ATP/ADP depolarises $\mathrm{E}_{\text {rev_ANT }}$ but it hyperpolarises

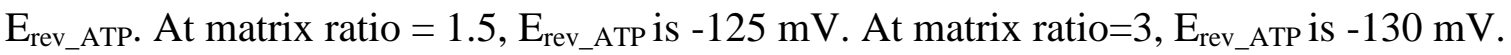

\section{The $\mathrm{E}_{\text {rev_ATP }}$ of ATP synthase is more hyperpolarised in cancer cells}

The coupling ratio of ATP synthase, $n$, is how many protons need to flow "downhill" for it to synthesise one ATP molecule from ADP and Pi. 2.7 protons need to flow through ATP synthase itself but the final value is one proton more than this: 3.7 [51]. This is because a proton is needed by the mitochondrial phosphate carrier to symport one Pi molecule into the mitochondrial matrix. Equation 1 employs this $n$ parameter and $n=3.7$ in Figure 1. The coupling ratio is widely believed to be equal for the "forward" and "reverse" modes of ATP synthase. That is, in the "reverse" mode, the hydrolysis of one ATP molecule can pump the same number of protons that are required to synthesise one ATP molecule in the "forward" mode. I suggest that this isn't true. The 2.7 value ascribed to ATP synthase itself likely holds. However, in the "reverse" mode there is no longer the need for Pi import and its associated proton cost. So, this renders $n=2.7$. Actually, Pi needs to be exported and this can be done by the ATP-Mg/Pi carrier (APC) and/or the phosphate carrier, which has an alternative mode that can perform an electroneutral exchange of a Pi molecule for a hydroxyl ion $\left(\mathrm{OH}^{-}\right)$. The latter could be suspiciously stretched to be considered proton import if one considers a hydroxyl ion, with its proton component, equivalent to a proton flow. However, the former definitely cannot be. Figure 3(C) shows the more hyperpolarised $\mathrm{E}_{\text {rev_ATP }}$ plot when $n=2.7$ instead of 3.7. The midpoint of the $\mathrm{E}_{\text {rev_ATP }}$ curve (where matrix ATP/ADP ratio $=1.5$ ) shifts from -125 to $-174 \mathrm{mV}$. If $n=2.2$, the midpoint shifts to $-215 \mathrm{mV}$ (not shown). Incidentally, the $\mathrm{E}_{\text {rev_ANT }}$ plot is unchanged.

ANT2 expression is under the control of the glycolysis regulated box (GRBOX), which regulates expression of machinery for the aerobic glycolysis operating state [53-54]. Also under this control is a gene for a $\beta$ subunit of ATP synthase [53]. The $\mathrm{F}_{1} \mathrm{~F}_{0}$ ATP synthase consists of two domains: a transmembrane proton translocating $\mathrm{F}_{0}$ domain (with subunits $\mathrm{ab}_{2} \mathrm{c}_{12}$ ) and a cytoplasmic ATP catalytic domain (with subunits $\alpha 3 \beta 3 \gamma \delta \varepsilon$ ) [88]. The two domains are attached by a "stalk" of subunits $\gamma$ and $\varepsilon$. This new $\beta$ subunit in the catalytic domain of ATP synthase may convey a different affinity constant, $K m$, for ADP and/or ATP ( $K_{w}$ and $K_{q}$ in Equation 1 respectively). Increasing $K_{w}$ and/or decreasing $K_{q}$ hyperpolarises

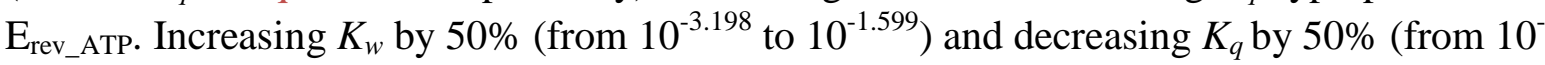
4.06 to $10^{-6.09}$ ) shifts the midpoint of the $\mathrm{E}_{\text {rev_ATP }}$ curve from -125 to $-185 \mathrm{mV}$, Figure 3 (D). 
As aforementioned, mitochondria in cancer cells export Pi and no longer have its import, driven by the pmf. So, the Pi level in the mitochondrial matrix is likely to be lower than in normal cells. If $[\mathrm{P}]_{\text {in }}$ is reduced hundred-fold from 10 to $0.1 \mathrm{mM}$, as in Figure $3(\mathrm{E})$, then the midpoint of the $E_{\text {rev_ATP }}$ curve shifts from -125 to $-158 \mathrm{mV}$. The $\mathrm{E}_{\text {rev_ANT }}$ plot is unchanged.

\section{$E_{\text {rev_ANT }}(A N T 1 / A N T 3)$ and $E_{\text {rev_ATP in cancer cells }}$}

Figure 4 shows these values modelled for cancer (panel B) and normal cells (panel A) using Equations 1-11. As compared to the normal cell parameters, the cancer equations have a fivefold reduction in the cytosolic ATP/ADP ratio ([ATP $]_{\text {out }}$ is maintained at $1.2 \mathrm{mM}$, [ADP $]_{\text {out }}$ is increased fivefold from 10 to $50 \mu \mathrm{M}$ ), the $\mathrm{H}^{+} / \mathrm{ATP}$ coupling ratio: $n=2.7$ instead of 3.7, matrix Pi is reduced twentyfold from 10 to $0.5 \mathrm{mM}$ and the matrix ATP/ADP ratio is doubled (if one reads the value on the $\mathrm{x}$-axis at $\mathrm{y}$-axis values: $\mathrm{y}=3$ for cancer panel and $\mathrm{y}$ $=1.5$ for normal panel). These cancer values are set by the rationale presented thus far and were chosen to present how the same equations used for normal cells can replicate the $\Psi_{\text {IM }}$ of cancer cells, all be it with different parameter values. In Figure 4, $E_{\text {rev_ANT }}=-115 \mathrm{mV}$, $\mathrm{E}_{\text {rev_ATP }}=-124 \mathrm{mV}$ for normal $(\mathrm{A})$; $\mathrm{E}_{\text {rev_ANT }}=-55 \mathrm{mV}, \mathrm{E}_{\text {rev_ATP }}=-211 \mathrm{mV}$ for cancer $(\mathrm{B})$. So, the cancer system has a more depolarised $E_{\text {rev_ANT }}$ (for ANT1/ANT3) and a more hyperpolarised $\mathrm{E}_{\text {rev_ATP. }}$ ANT2 is discussed in the next section.

\section{What is the $E_{\text {rev_ANT }}$ of ANT2?}

Firstly, note that ADP/ATP exchange by any ANT isoform is not energy dependent. It proceeds with high activity when the mitochondria are completely depolarised by uncouplers; in which case ADP and ATP are transported in both directions at nearly equal rates [81]. With the orientation of ANT1 and ANT3, a hyperpolarised $\Psi_{\mathrm{IM}}$ (negative inside) favours the export of $\mathrm{ATP}^{4-}$ and import of $\mathrm{ADP}^{3-}$. How energisation of the membrane affects the exchange by ANT2, in its postulated inverse orientation, is not known. The exchange of ANT1 in an inverse orientation has been studied in sub-mitochondrial vesicles produced by sonication. The vesicles typically form "inside-out" with their mitochondrial matrix face exposed on the outside of the vesicle [89]. In this inverted orientation, the exchange seems to occur without influence by the membrane potential (isn't altered by uncoupling chemicals). But then there is the complication that how much membrane potential do these vesicles actually retain or sustain?

I think it is fair to suggest, in the absence of direct data, that at membrane potentials that ANT1 and ANT3 - in their "conventional" orientation - are exporting ATP: ANT2, in its "inverted" orientation, is importing ATP. 


\section{The biophysics of $\Psi_{I M}$ in cancer cells}

In cancer cells $\Psi_{\mathrm{IM}}$ is hyperpolarised at $\sim-220 \mathrm{mV}$. I suggest because $\mathrm{E}_{\text {rev_ATP }}$ is $\sim-220 \mathrm{mV}$ in cancer cells. And that $\Psi_{\mathrm{IM}}$ oscillates around this point. When more depolarised, ATPase is in it "reverse" mode and pumping protons at the expense of ATP hydrolysis to ADP and Pi. ANT2 imports ATP to service this hydrolysis and exports the ensuing ADP. The ATP-Mg/Pi carrier (APC) imports further ATP and exports Pi. Glycolysis in the cytoplasm synthesises ATP from this ADP and Pi. APC is electroneutral. The "reverse" mode of ATPase is hyperpolarising as is the $\mathrm{ATP}^{4-}$ import and $\mathrm{ADP}^{3-}$ export by ANT2. These hyperpolarising forces drive $\Psi_{\text {IM }}$ to $E_{\text {rev_ATP }}$ and then past it at which point ATPase switches into its depolarising "forward" mode. This then depolarises $\Psi_{\text {IM }}$ back towards E rev_ATP. So $_{\text {IM }}$ oscillates around $\mathrm{E}_{\text {rev_ATP }}(\sim-220 \mathrm{mV})$. At $\mathrm{E}_{\text {rev_ATP }}$ precisely there is no drive for proton conductance or pumping through ATPase, so oscillating around this point ensures little ATP generation but not much ATP hydrolysis either. It is a "cheap" way to hold $\Psi_{\mathrm{IM}}$ at a hyperpolarised potential, safely well away from "dangerous" depolarised potentials that could open PTP and drive apoptosis. In cancer cells, ANT1 and ANT3 are expressed at low levels and so are irrelevant. However, if by an experimental intervention they are expressed at significant levels, they can kill the cancer cell. In cancer cells, the $\mathrm{E}_{\text {rev_ANT }}$ of ANT1 and ANT3 are abnormally depolarised. This means that their depolarising "forward" mode of operation - $\mathrm{ATP}^{4-}$ export, $\mathrm{ADP}^{3-}$ import - depolarises $\Psi_{\mathrm{IM}}$ towards their "dangerously" depolarised $\mathrm{E}_{\text {rev_ANT }}$ value. What is more, their export of ATP undermines the import of ATP by ANT2 and denies it to ATPase. Hence the hyperpolarising "reverse" mode of ATPase, wherein it needs ATP to pump protons, is compromised. Thus, it isn't able to combat the depolarisation conveyed by ANT1 and/or ANT3. They have such depolarised E Erev_ANT values that the driving force for their depolarising exchange is immense at even rather modestly hyperpolarised potentials e.g. $-100 \mathrm{mV}$.

\section{An alternative biophysics of $\Psi_{I M}$ in cancer cells}

The prior account assumes that cancer mitochondria are looking to maintain $\Psi_{\mathrm{IM}}$ by the lowest, "cheapest" ATP spend. However, an alternative view is that during aerobic glycolysis mitochondria are tasked with burning through ATP as a specific aim in itself [90]. To lower [ATP] in the cytoplasm, release key glycolytic enzymes from negative feedback by ATP [1, 90]), and permit high glycolytic rates. In proliferating cells, glycolysis isn't just tasked with ATP production. It has important roles in shuttling its metabolic intermediates into macromolecular biosynthesis pathways [86-87]. The rapidly proliferating cell may have to forsake ATP to facilitate this [90]. Low cytosolic and high mitochondrial ATP/ADP ratios produce a hyperpolarised $\mathrm{E}_{\text {rev_ATP }}$ and depolarised $\mathrm{E}_{\text {rev_ANT }}$ for ANT1 and ANT3 (which are expressed at low levels). Proton pumping by ATP synthase (hyperpolarising), fuelled by ATP entry through ANT2 (hyperpolarising) and the ATP-Mg/Pi carrier (electroneutral), may be balanced electrically by ATP export/ADP import (depolarising) and/or proton leak 
(depolarising) by ANT1 and/or ANT3. ANT1 seems to convey a basal proton leak that ANT2 doesn't [91-93]. This electrical balance (at -220 mV) may keep $\Psi_{\text {IM }}$ consistently and sufficiently depolarised to $\mathrm{E}_{\text {rev_ATP }}\left(\mathrm{E}_{\text {rev_ATP }}<-220 \mathrm{mV}\right)$ such that ATP hydrolysis occurs at high rates. The amount of ANT1 and ANT3 is low but at this point of balance, $\Psi_{\mathrm{IM}}$ is sufficiently hyperpolarised to their $\mathrm{E}_{\text {rev_ANT }}$ that they produce crucial activity, despite being expressed at low levels. This is all a balance and will naturally have its fluctuations but if ANT1 and/or ANT3 are overexpressed: it depolarises $\Psi_{\text {IM }}$ out of this balance and into a spiral of depolarisation, PTP opening and apoptosis. But then similarly if ANT1 (particularly) is underexpressed it will disturb the balance and $\Psi_{\mathrm{IM}}$ will hyperpolarise and oscillate around

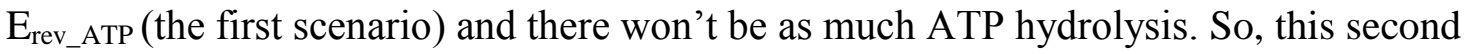
account details a role for ANT1 and/or ANT3 in aerobic glycolysis where the first one rendered them redundant. It suggests that not just overexpression of ANT1 will perturb function, but under-expression of ANT1 will disturb function also. Indeed, ANT1 overexpression is pro-apoptotic [78] and ANT1 under-expression can kill cancer cells also [94]. In the latter case, cancer cells appear to die because of oxidative damage [94]. I postulate that ANT1 loss renders a lower rate of ATP hydrolysis in mitochondria and thence the glycolytic rate in the cytoplasm is lower, because of ATP feedback. A postulated role of enhanced glycolysis is protection from oxidative damage [73]. Indeed it conveys so much protection that it can gift cancer cells immortality [73]. A lower glycolytic rate conveys less protection and death. A high glycolytic flux permits a high flux into the pentose phosphate pathway (PPP) that branches from glycolysis. It produces NADPH from $\mathrm{NADP}^{+}$, which is needed for glutathione (GSH)-dependent anti-oxidant mechanisms. To protect, GSH needs to be in its reduced form and NADPH puts it into this reduced form (as it is converted to NADP ${ }^{+}$). GSH is needed by glutathione peroxidase (GP), which converts hydrogen peroxide (a ROS) into water. Upstream, superoxide dismutase (SOD) converts superoxide $\left(\mathrm{O}_{2} \bullet-\right.$, a $\left.\mathrm{ROS}\right)$ into hydrogen peroxide. Increased GP activity will pull through greater SOD activity. So, less ANT1 produces less NADPH, less oxidative protection and death (by paraptosis). This is a different interpretation than that in the paper itself [94]. So, an imposed hyperpolarisation (e.g. by ANT1 knockdown) of the $\Psi_{\mathrm{IM}}$ in cancer cells may be able to kill them, in addition to an imposed depolarisation (e.g. by ANT1 overexpression).

\section{Re-interpreting the data of [94]}

We both agree death is by oxidative damage. [94] suggests that lower ANT1 generates more ROS. I suggest, instead, that it compromises the enhanced ROS mitigation apparatus of cancer cells, by reducing their spurious ATP hydrolysis, thence their glycolytic rate, PPP rate and NADPH production. [94] talk of electron fumbles by the respiratory chain generating ROS, but during aerobic glycolysis electrons don't passage along this chain. The higher ANT2 level in these cancer cells suggests they are utilising aerobic glycolysis; as does the lack of response to atractyloside (ATR) or bongkrekic acid (BKA). These drugs would kill a cell using aerobic respiration. They inhibit ATP/ADP exchange by ANT1 (but not ANT2 because of its inverted orientation; a prediction of this manuscript). They observe siRNA 
knockdown of ANT2 to have no effect but then as aforementioned, a working knockdown of ANT2 can require shRNA [76].

They observe enhanced glucose consumption, and presumably glycolysis, 72 hours after ANT1 has been reduced (by siRNA interference). But this could be an after-effect once the increase in un-sequestered ROS has committed the cell to death. It could be due to the active processes of paraptosis (a form of programmed cell death; an active process) consuming ATP, lowering ATP levels and reducing its allosteric feedback on key glycolytic enzymes and thus permitting a higher glycolytic rate.

The basal proton leak function of ANT1 can work even when its nucleotide exchange function is blocked by carboxyatractylate (CAT) [93] (and so maybe also ATR or BKA). It is likely to be this proton-leak function, and its loss, that is important in this case. So, uncoupling may be a physiological feature not just of aerobic respiration ("uncoupling to survive theory" [95]), but aerobic glycolysis also.

However, in contrast to [94], ANT1 knockdown by siRNA did not cause cancer cell death in a different study by a different group in a different cancer cell line [77]. Furthermore, ANT1 genetic knockout animals can live to adulthood [92]. So, this suggests that it isn't vital to aerobic glycolysis (in the embryonic stage) or aerobic respiration in adult cells. However, there may be developmental adaptations in these knockout animals that make them nontypical e.g. an up-regulation of ANT3. Also, the knockout may not be complete.

It is unclear whether ANT1 associated proton leak is by a specific pathway within the carrier. Or, since the proton conductance is not dependent on the function or turnover of ANT, it may occur at the protein-phospholipid interface. It is still unclear to what extent this particular "function" is tractable to pharmacology. It is interesting that ANT1 conveys a proton leak that ANT2 doesn't [91-92], which could be related to the postulated inverse orientation of ANT2.

\section{Cancer cells reduce ROS at source and sink}

I propose that during aerobic glycolysis, ROS are confronted at source and sink. OXPHOS is shunted leading to less ROS generation and the mitigation system is upregulated leading to more ROS mitigation. ROS generation is determined by the redox state of $\mathrm{NAD}^{+}$, while the $\mathrm{NADP}^{+}$redox state is pivotal to antioxidant defence. As compared to normal cells, cancer cells decrease NADH and increase NADPH levels. The latter may carry over to confer 
greater protection if the cancer cell periodically switches into aerobic respiration.

Investigators have reported cancer cells to have higher NADH levels than normal cells [97].

But their spectroscopy can't discriminate between NADH and NADPH and I suggest they are actually observing higher NADPH levels in cancer cells. Indeed, later studies with a spectroscopy that can distinguish between these two species reports higher NADPH, rather than NADH, in cancer cells [98]. Cancer may be combatted by increasing NADH [34] and/or lowering NADPH. This could be achieved by transfecting cancer cells with a mutant lactate dehydrogenase (LDH) that uses NADPH rather than NADH. Such a form has been engineered for a prokaryote $\mathrm{LDH}$ [99]. In a prior paper, I propose exogenous NADH as a cancer medicine [34].

\section{UCP2 depolarises $\Psi_{\text {IM }}$ past $E_{\text {rev_ATP }}$ and primes greater ATP hydrolysis by ATP synthase}

Uncoupling proteins (UCPs) passage protons through the inner mitochondrial membrane, dissipating their electrochemical potential as heat $[3,100]$. UCP1 is implicated in thermogenesis. The role of its homologues - UCP2, UCP3, UCP4 and UCP5 - is less clear. If $\Psi_{\mathrm{IM}}$ becomes too great during OXPHOS, there is greater ROS production [95]. A postulated role of UCP2 is to reduce $\Psi_{\mathrm{IM}}$ in this scenario and decrease ROS production [101]. UCP2 can be activated by reactive oxygen species (ROS), perhaps forming part of a negative feedback mechanism that shunts excessive ROS production [96]. ROS can produce mutations, which can lead to cancer [100]. A lower UCP2 activity can confer a greater risk of cancer [101]. However, once cancer develops - and it is utilising aerobic glycolysis - there is evidence that it upregulates UCP2 activity above that of normal cells [101]. Indeed, it is overexpressed in many cancers [101-102]. I reason that UCP2 conveys depolarisation that keeps $\Psi_{\mathrm{IM}}$ depolarised to $\mathrm{E}_{\text {rev_ATP, }}$ such that significant ATP hydrolysis can occur, the cytoplasmic ATP/ADP ratio is kept low, glycolytic rate is high, PPP rate is high, NADPH levels are high and ROS are significantly sequestered. Indeed, UCP2 silenced cancer cells show a more hyperpolarised $\Psi_{\mathrm{IM}}$, a greater cytoplasmic ATP/ADP ratio and less lactate release than

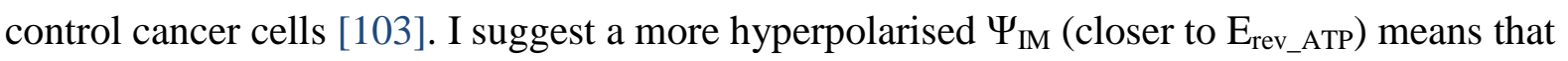
ATP synthase cannot hydrolyse as much ATP: this is why the cytoplasmic ATP level is higher, the glycolytic rate is lower and less lactate is released. I would argue that these cells have a lower ROS mitigation capability. Indeed, suppression of UCP2 (siRNA) results in greater ROS levels and the induction of apoptosis in cancer cells (during hypoxia, so any OXPHOS effects are redundant) [104]. Furthermore, overexpression of UCP2 is antiapoptotic for cancer cells (during hypoxia, so any OXPHOS effects are redundant) [104]. Many anti-cancer drugs exert their effect by generating ROS. UCP2 inhibition potentiates their effect [105], perhaps by undermining the cancer cell's ROS mitigation apparatus. For example, genipin is a UCP2 inhibitor. It sensitizes cancer cells to cytotoxic agents by decreased proton leak and increased ROS levels [106]. Genipin has been reported to induce apoptotic cell death in cancer cells via increased ROS [107-109]. UCP2 expression is higher in a modified cancer cell line lacking mitochondrial DNA, which cannot use OXPHOS and 
respires fully by aerobic glycolysis; UCP2 inhibition by genipin impairs the tumorigenicity of this cell line [102]. When UCP2 is overexpressed in the parent cancer cell line, that still has mitochondrial DNA, it decreases its $\Psi_{\mathrm{IM}}$ and increases its tumorigenicity [102]. UCP2, in addition to conferring a proton leak, is involved in the switch into aerobic glycolysis [103, 109-110]. siRNA-mediated UCP2 knockdown leads to reversal of the glycolytic phenotype in some cancer cells [111]. So, we see a link between aerobic glycolysis and resistance to chemotherapy. Cisplatin, one of the most important chemotherapeutics found thus far, acts by inhibiting UCP2 (amongst other targets) [112].

UCP2 exports pyruvate, oxaloacetate and related $\mathrm{C} 4$ compounds from mitochondria, denying them to aerobic respiration and helping the switch to aerobic glycolysis $[102,103,109]$. Indeed, in quiescent human pluripotent stem cells, high levels of UCP2 expression prevent mitochondrial glucose oxidation, favouring aerobic glycolysis, whereas during cell differentiation, UCP2 is repressed and glucose metabolism is shifted toward mitochondrial oxidation [110]. The former can be applied to cancer cells with our construct of equivalence in the use of aerobic glycolysis - between cancer and ES cells. Furthermore, ROS are substantially increased in UCP2 shRNA knockdown pluripotent stem cells and result in elevated apoptosis [110].

This UCP2 role in cancer cells gives two contrasting points of attack. One can reduce UCP2 activity to hyperpolarise $\Psi_{\mathrm{IM}}$, reduce ATP hydrolysis, increase unmitigated ROS levels and bring cancer cell death. An alternative tact is to increase UCP2 expression/activity - to increase its depolarising proton flow - to collapse the mitochondrial $\Psi_{\mathrm{IM}}$ in cancer cells and bring apoptosis. Low doses of the uncoupler, FCCP, can replicate the lower ROS and antiapoptotic effect of UCP2 overexpression in cancer cells; higher doses of FCCP produce cell death [105]. This FCCP experiment yields insight into the two disparate paths to killing a cancer cell via modulation of UCP2 proton leak.

\section{A drug that hyperpolarises $\Psi_{I M}$ will convey a specific anti-cancer action e.g. nigericin}

The antibiotic nigericin is an ionophore that performs $\mathrm{K}^{+} / \mathrm{H}^{+}$exchange [3]. In normal cells, nigericin decreases the $\delta \mathrm{pH}$ component of the pmf, which prompts a compensatory increase in the hyperpolarisation of $\Psi_{\mathrm{IM}}(\sim 30 \mathrm{mV})$ to maintain the pmf [113]. If it hyperpolarises $\Psi_{\mathrm{IM}}$ in cancer cells, and it does in HeLa cells [114], this may be a basis to its observed anti-cancer action in vitro and in vivo [115]. Ionomycin can also cause $\Psi_{\mathrm{IM}}$ hyperpolarisation $(\sim 10 \mathrm{mV})$ [113] and this may be a basis to its observed anti-cancer action in vitro and in vivo [116]. I suggest that an ionophore species that hyperpolarises $\Psi_{\mathrm{IM}}$ will convey an anti-cancer action. 
Figure 3(F) shows how nigericin might cause a hyperpolarisation in $\Psi_{\mathrm{IM}}$ in cancer cells. Nigericin acidifies the matrix and correspondingly increases the $\mathrm{pH}$ of the intermembrane space. Figure $3(\mathrm{~F})$ shows matrix $\mathrm{pH}=6.38$, instead of 7.38, and intermembrane space $\mathrm{pH}=$ 8.25, instead of 7.25. Given the $\mathrm{pH}$ parameters of Equation 1, this moves $\mathrm{E}_{\text {rev_ATP }}$ to a more hyperpolarised potential. This increases the drive for, and action of, the hyperpolarising, proton-pumping "reverse" action of ATPase. At the same time, depolarising forces are diminished because $E_{\text {rev_ANT }}$ also moves to a more hyperpolarised potential. Hence $\Psi_{\text {IM }}$ hyperpolarises; it moves closer to $\mathrm{E}_{\text {rev_ATP }}$ than previously, so reducing the amount of ATP hydrolysis, and it may even converge upon the new hyperpolarised $E_{\text {rev_ATP }}$ value, which would dramatically reduce the amount of ATP hydrolysis. This reduces the glycolytic rate which decreases the NADPH mediated ROS mitigation apparatus of cancer cells which promotes ROS mediated apoptosis. Furthermore, it sensitizes the cancer to other drugs or means (e.g. radiation) that increase ROS levels.

\section{Uncoupling Cancer: a drug that can depolarise $\Psi_{I M}$ will convey a specific anti-cancer action}

Exogenous uncouplers transport protons across the inner mitochondrial membrane and dissipate the pmf as heat [3]. Eukaryotes must maintain a hyperpolarised $\Psi_{\mathrm{IM}}$ or they will undergo apoptosis [5]. Aerobic respiration hyperpolarises $\Psi_{\mathrm{IM}}$ as it produces ATP; Aerobic glycolysis consumes ATP to produce a hyperpolarised $\Psi_{\mathrm{IM}}$. Under the challenge of an uncoupler drug, the former is more sustainable than the latter. Cancer cells use aerobic glycolysis, some or all of the time, and so will be exquisitely sensitive to uncoupling drugs. Furthermore, we have shown that cancer cells may have a very delicately balanced $\Psi_{\text {IM }}$ value, which if mildly depolarised can tip into a runaway depolarisation because of the excessively depolarised $E_{\text {rev_ANT }}$ values (for ANT1 and ANT3) in cancer cells. By contrast, in normal cells, the $\mathrm{E}_{\text {rev_ANT }}$ values are at more hyperpolarised values that are protective and act against excessive depolarisation.

Of course, a cancer cell could switch out of aerobic glycolysis and start using aerobic respiration to counter the uncoupling threat. But no, they can't. Not long term. There is growing evidence that cancer cells must use aerobic glycolysis for at least a component of their proliferation cycle: constitutively activating OXPHOS kills cancer cells [19, 34, 37,] or halts their proliferation [18, 38-39] via ROS production [19, 34].

Additionally, because cancer cells have a more hyperpolarised $\Psi_{\mathrm{IM}}$ than normal cells, uncouplers will be selectively targeted to, and accumulated by, cancer cells. Uncouplers are lipophilic and can be cations or anions [117]. They will be more targeted to the mitochondrial matrix and intermembrane space of cancer cells respectively. At these locations they are 
primed to uncouple. If we consider, for example, that $\Psi_{\mathrm{IM}}=\sim-220 \mathrm{mV}$ in cancer and $\Psi_{\mathrm{IM}}=$ $\sim-140 \mathrm{mV}$ in normal cells. This is an $80 \mathrm{mV}$ difference which, using the Nernst equation $(\mathrm{T}=$ $300 \mathrm{k}$ ), suggests that lipophilic uncouplers will be accumulated and retained by cancer cells $\sim 20$ times more if they are single charged and $\sim 500$ times more if double charged. These differentials are significant. They mean that cancer cells will be selectively targeted and that, crucially, they will sequester the poison from normal cells. The more aggressive the cancer, the more hyperpolarised its $\Psi_{\mathrm{IM}}[14-16]$ and the more it will be targeted.

A major problem in cancer therapy is that cancer cells can accrue DNA mutations which confer drug resistance. This is a problem for drugs that target or rely (e.g. for transport) on DNA encoded proteins. The cancer cell develops a DNA mutation that confers a change in the protein structure which means the drug can no longer interact with it in the same way. Protonophores do not interact with or rely on proteins to collapse $\Psi_{\mathrm{IM}}$ and kill cancer cells.

The cytoplasm is, and needs to be, neutral in normal and cancer cells [118-120]. Tumours are acidic, normal tissue is neutral [120-122]. This is likely because cancer cells, unlike normal cells, are using aerobic glycolysis and excreting lactate and protons through the monocarboxylate symporter (a promising cancer drug target). The more aggressive the cancer is, the more acidic its tumour [123]. So, cancer cells, unlike normal cells, must maintain their intracellular $\mathrm{pH}$ above their extracellular acidity and protonophores will shuttle protons, undermine this homeostasis and kill cancer cells; a prediction.

\section{Uncouplers can kill cancer cells}

2,4-dinitrophenol (DNP) and FCCP are uncouplers. In cancer cells, they cause cell cycle arrest at low doses and apoptosis at higher doses, via depolarising $\Psi_{\mathrm{IM}}$ which opens PTP [124-125]. The uncouplers: moronone [126], CCCP [127], clusianone [128] and hyperforin [129] also kill cancer cells. So, uncouplers can kill cancer cells. However, the crux issue is: can they kill cancer cells whilst leaving normal cells unharmed?

In vitro, F16 - a lipophilic cation uncoupler (a DLC) - kills cancer cells but not normal cells [11]. In vitro, nemorosone - a lipophilic anion uncoupler - kills HepG2 cancer cells ( 75\% cell death) but not non-cancer human embryonic kidney HEK293T cells to the same degree ( $10 \%$ cell death) [130]. So, there is a possible selectivity of action; which might be enhanced if cancer and normal cells were to be tested side-by-side in the same in vitro assay. Because cancer cells, with their greater affinity for a charged lipophilic protonophore (as previously discussed), may accumulate and sequester it from the normal cells. A DLC 
derivative of gallic acid, $\mathrm{TPP}^{+} \mathrm{C}_{10}$, can uncouple and selectively kill cancer cells in vitro and in a singenic mouse model [131].

Valinomycin depolarises $\Psi_{\mathrm{IM}}$; nigericin hyperpolarises $\Psi_{\mathrm{IM}}[3]$. As aforementioned, depolarisation or hyperpolarisation of $\Psi_{\mathrm{IM}}$ may kill cancer cells and these drugs both demonstrate an anti-cancer activity $[115,132]$. Together, valinomycin and nigericin can uncouple $\mathrm{H}^{+}$, while $\mathrm{K}^{+}$cycles around the membrane [3]. This combined uncoupling activity should be tested against cancer cells. Coumarins comprise a structurally diverse group of natural compounds found in a variety of plant sources [133-135]. Some coumarin molecules (mammea A/BA, mammea A/BB) can reduce tumour weight by $83 \%$ in test animals by halting the cell cycle and inducing apoptosis selectively in cancer cells, by an unknown mechanism [133]. Possibly by uncoupling $\Psi_{\mathrm{IM}}$ : mammea A/BB collapses the $\Psi_{\mathrm{IM}}$ of the Leishmania amazonensis parasite [134]. A different coumarin molecule (mammea E/BB), with an anti-cancer action, has been shown to be an anionic protonophore with an uncoupling potency equivalent to that of FCCP [135].

Uncoupling chemicals can shuttle protons alone (e.g. DNP) or in interaction with a transmembrane protein in the inner mitochondrial membrane e.g. ANT [136]. There are other, further conceivable mechanisms to uncouple e.g. neutralising a negative molecular species residing in the mitochondrial matrix, shuttling a negative species out of the matrix, stimulating UCP activity or the intrinsic, basal uncoupling activity of other inner mitochondrial membrane proteins e.g. ANT.

Phenols, benzimidazoles, N-phenylanthranilates, salicylanilides, phenylhydrazones, salicylic acids, acyldithiocarbazates, cumarines, and aromatic amines can induce uncoupling [137]. I anticipate that these will have an anti-cancer activity and merit investigation.

\section{2,4-dinitrophenol as an anti-cancer drug}

2,4-dinitrophenol (DNP) is a lipophilic anionic (-1) protonophore. It can cross membranes protonated, then lose the proton and return as the anion, then reprotonate and repeat the cycle. It was legally (1933-38, USA), and is now illegally, used as dieting drug. It can be bought over the internet and does cause weight loss [138]. However, the therapeutic margin between a slimming and poisonous dose, which can cause death by overheating [139], is close (3-10 fold) [136]. There were reports of cataracts as a side effect in the 1930s but this relation has been later queried [140]. In the correct doses, the deleterious effects of DNP are few [141]. It has been taken by hundreds of thousands of people, often without proper medical consultation, and typically without ill effect [141]. From 1900-2011 (>100 years), there were 
62 deaths in the medical literature attributed to DNP [139]; but some of these were intentional, suicide acts. Although not appropriate as a weight loss pharmaceutical, DNP may be useful as a cancer drug. The risk-reward axis is different for terminal patients - with just days, weeks or months to live - than for healthy adults chasing aesthetic goals. Moreover, a further distinction is that the cancer, with its hyperpolarised $\Psi_{\mathrm{IM}}$, will accumulate and sequester the drug from normal cells. Incidentally, low doses of DNP increase lifespan in healthy mice [142].

\section{DLCs can enhance uncoupling by anionic uncouplers e.g. DNP}

The negative DLC and anionic uncoupler will be more targeted to cancer cells because of their more hyperpolarised $\Psi_{\mathrm{IM}}$. Thence this enhancement effect, by the DLC upon uncoupling activity [143], will be more targeted to cancer cells. This may be especially pronounced if a DLC with two positive charges is used e.g. dequalinium. If the disparity in $\Psi_{\mathrm{IM}}$ is $\sim 80 \mathrm{mV}$ between normal and cancer cells, for example, dequalinium will localise $\sim 500$ times more to the mitochondria of cancer cells. So, the enhancement effect will be $\sim 500$ times more pronounced in cancer cells. It will permit lower concentrations of uncoupler be used. Relevantly, dequalinium has an anti-cancer activity of its own in vitro and in vivo [44].

\section{Drugs that selectively inhibit the reverse, and not the forward, mode of ATP synthase will selectively kill cancer cells}

The $\Psi_{\text {IM }}$ of cancer cells could be collapsed by a drug that inhibits the reverse, ATP hydrolysing, but not the forward, ATP synthesising, operation of ATP synthase. There are a number of such drugs, based around five different molecular scaffolds (Figure 5), and listed in Table 1 [144]. These drugs may also kill cancer cells by disrupting their $\mathrm{pH}$ homeostasis. Unlike normal cells that sit in neutral tissues, cancer cells reside in acidic tumours [120-122] and express ATP synthase at their plasma membrane [145]. They may be using its "reverse" mode to excrete protons. The drugs of Table 1 should be harmless to normal cells as they aren't using this "reverse" mode of ATP synthase. I urge their trialling on cancer cells and in xenograft mouse models [146]. Especially BMS-199264 [147-149]; it is already being investigated as a protective agent during ischemia [147-148] and can cross plasma and mitochondrial membranes [148].

Promoted expression or increased activity of endogenous IF-1 also blocks the "reverse" mode of ATPase and is another direction for anti-cancer drug development. BTB06584 [150] and diazoxide [144] can block this mode through IF-1 and should be tested for anti-cancer activity. Analogues of IF-1, and antibodies of its binding site on ATP synthase, should be explored. Melittin and the 25-residue mitochondrial import pre-sequence of yeast cytochrome oxidase subunit IV (and its synthetic derivatives: Syn-A2, Syn-C, $\Delta 11,12$ ) can act upon ATP 
synthase like IF-1 [144] and should be tested for anti-cancer activity. Indeed, melittin has anti-cancer activity in vitro and in vivo [151].

The $\Psi_{\mathrm{IM}}$ of cancer cells could also be collapsed by a drug or DNA/RNA that promotes the expression/activity of ANT1, ANT3, UCP2 [78-79]; or a drug/DNA/RNA that decreases the expression/activity of ANT2 [76]. As aforementioned, the (postulated) inverse orientation of ANT2 in the membrane opens many prospects for drug design, wherein the drug is specific to ANT2 (cancer cells) rather than ANT1/ANT3 (normal, adult cells). Drugs may attack the trafficking apparatus that inverts ANT2; if not inverted it would have incorrect activity (prediction). ANT2 expression is under the control of the glycolysis regulated box (GRBOX), which regulates expression of machinery for the aerobic glycolysis operating state [53-54]. This is a possible cancer drug target. These therapies can be utilised in combinations amongst themselves or with other treatments.

These candidate drugs, or DNA/RNA, can be targeted to the negative mitochondrial matrix, and thence disproportionally to cancer cells because their matrix is more negative, by attachment to a DLC. For example, they can be attached to a lipophilic triphenylphosphonium $\left(\mathrm{TPP}^{+}\right.$) cation(s) [152-153], or to its methylated form (TPMP ${ }^{+}$) or to a $\mathrm{N}$-arylpyridinium ion [154]. The attachment can be via esterase labile ester bonds that are hydrolysed by esterase enzymes in the mitochondrial matrix, releasing the payload [152]. Or a linkage that is broken by hydrogen peroxide, a ROS present in the matrix [155]. Or it may not be necessary for the linkage to be broken if it doesn't prevent required interactions. Using dequalinium, or $\mathrm{P} 2 \mathrm{C} 5$ or $\mathrm{P} 2 \mathrm{C} 10$, as the localising DLC has the advantage that they each have two positive charges and so will be more localised than mono-cations [156-157]. It may be that multiple DLC molecules can be joined together to produce even stronger targeting frames. The more DLC molecules conjoined, the higher the charge of the conjugate and the greater it's targeting to cancer cells, if it can retain lipid solubility. The lipophilic character may be diminished but this will be equivalent for cancer and normal cells and won't affect targeting. Multiple $\mathrm{TPP}^{+}$cations have been used relatively unsuccessfully [158] and successfully [158-159] to convey increased targeting.

Atractyloside (ATR), carboxyatractyloside (CAT), epiatractylate (epi-ATR), coffee-ATR, wedeloside, $\mathrm{AppCCl}_{2} \mathrm{p}$ (adenosine-5'-[ $\beta, \gamma$-dichloromethylene $]$ triphosphate; a metabolite of clodronate) or ApppI (triphosphoric acid 1-adenosin-5'-yl ester 3-(3-methylbut-3-enyl) ester) are inhibitors of ANT, acting on its "c-side" [81, 160-161]. Antibodies can be produced against elements on the "c-side" and these may act as further ANT inhibitors. These drugs and antibodies aren't lipid soluble and so may not inhibit ANT2, which I predict is inverted and has its "c-side" in the mitochondrial matrix. However, they may be able to permeate this membrane if they are attached to delocalised lipophillic cations (DLC), conferring them 
lipophilic character and a net positive charge(s). Perhaps the attachment(s) can be via an ester bond, hydrolysed by esterases in the matrix [152]. Their targeting to the mitochondrial matrix would make them harmless to normal cells, with no relevant vulnerability there, but deadly to cancer cells using an inverted ANT2. If $\Psi_{\mathrm{IM}}=\sim-140 \mathrm{mV}$, the net positive complex will accumulate $\sim 225$ times more in the matrix than in the cytoplasm and if $\Psi_{\mathrm{IM}}=\sim-220 \mathrm{mV}$, as in cancer cells, it will be $\sim 5000$ times more; $~ 25$ million times more if the complex is net double positive (Nernst equation, $\mathrm{T}=300 \mathrm{~K}$ ).

Alternatively these drugs, or others, could be delivered to the mitochondrial matrix by a tiered liposome delivery system. The larger, outer liposome confers passage into the cell of the secondary, smaller, constituent liposome(s) which themselves confer passage past the outer mitochondrial membrane (OMM) for the tertiary, smaller constituent liposome(s) which passage the drug past the inner mitochondrial membrane (IMM) and into the matrix. Only two liposome tiers, rather than three, will be needed if the secondary liposomes can passage the OMM through VDAC channels. The number of required tiers will be cut if the initial, primary liposome is internalized by endocytosis (and so acquires a further bilayer upon cellular entry). Positive molecules can be embedded into the membrane of liposomes to assist in targeting to the negative mitochondrial matrix or a transmembrane potential (negative inside) can be attributed to the liposomes. Targeting molecules can be embedded in liposomes to piggyback upon physiological trafficking processes. Some alternative, tested, and already successful, liposome delivery systems, to mitochondria, are described in [154]. Alternatively, or in addition, these drugs or others could be delivered by attachment to membrane permeant peptides e.g. penetratin or the herpes virus protein VP22 [154, 162].

Antibodies can be produced against elements on the "m-side" of the ANT and these may act as further ANT inhibitors. They likely won't be lipid soluble and so won't be able to access and inhibit ANT1 and ANT3, with their "m-side" in the mitochondrial matrix. However, assuming they can passage into the cell (e.g. via liposome entry), they may access the "mside" of ANT2, which faces the cytoplasm (prediction). So, they would be ANT2 specific inhibitors. They could be attached to a lipophilic anion, which would target them to the mitochondrial intermembrane space. Eosin maleimide (EMA) is membrane impermeable and can only bind the "m-side" of ANT [81]. It could be used in an experiment to test if ANT2 is inverted in mitochondria isolated from cancer cells.

\section{A drug that inhibits ATP hydrolysis, and not synthesis, by ATP synthase (e.g. BMS- 199264) in combination therapy with an uncoupling drug (e.g. DNP)}

An uncoupling drug applied with a drug that inhibits the "reverse" mode of ATPase but not its "forward" mode - e.g. BMS-199264 - could bring devastation to cancer cells and leave 
normal cells unharmed. There would be significant synergy of action between these two drugs. In cancer cells, the uncoupler (e.g. DNP) would act to collapse $\Psi_{\text {IM }}$ and BMS-199264 would remove its means to counter this collapse. Crucially, it would lower the amount of uncoupling drug that needs to be given which would aid the safety profile, lowering the risks of the patient overheating. Inhibiting ANT2 would equivalently inhibit the "reverse" mode of ATPase because it would deny it ATP. So, such a drug would also lower the amount of uncoupling drug needed; as would promotors of ANT1 and ANT3 activity.

\section{An uncoupler in combination therapy with dichloroacetate (DCA)}

DCA inhibits pyruvate dehydrogenase kinase (PDK). This decreases PDK inhibition of pyruvate dehydrogenase (PDH) and permits pyruvate to enter the Krebs cycle and OXPHOS to proceed [19]. DCA selectively kills cancer cells in vitro and in vivo [19], and has caused much excitement [163], but its breakdown products can cause neuropathy [164-166]. DCA acts by constitutively switching on OXPHOS and the ROS produced kills cancer cells [19]. An uncoupler will synergise DCA action by increasing the OXPHOS and ROS production rate. So, it will permit lower DCA concentrations to be used, which will diminish DCA side effects. DCA will reciprocally permit lower uncoupler concentrations to be used (e.g. DNP), which will diminish uncoupler side effects. In a prior paper I proposed exogenous NADH as an anti-cancer drug [34]. I suggest it kills cancer cells as DCA does, by constitutively switching on OXPHOS (by conveying it substrate) [34]. However, unlike DCA, there is likely to be few side-effects as it's a natural metabolite. It could be used in combination with DCA and/or an uncoupler.

\section{Conclusion}

Cancer cells have a more hyperpolarised $\Psi_{\mathrm{IM}}$ than normal cells ( - $220 \mathrm{mV}$ compared to $140 \mathrm{mV}$ ). This discrepancy suggests that different processes generate $\Psi_{\mathrm{IM}}$ in cancer cells, which may be compromised to selectively kill them. This paper identifies these processes and prospective anticancer drugs, which I hope will be entered into animal and clinical studies. For example, BMS-199264, which blocks the reverse, ATP hydrolysing, but not the forward, ATP synthesising, operation of ATP synthase.

Funding: The author wrote this paper without any financial support.

Keywords: systems biology, in silico, cancer biophysics, rational drug design, Warburg effect, aerobic glycolysis, cancer drug, metabolic oncology, cancer metabolism, delocalized lipophilic cation, DLC, BMS-199264, NADH, NADPH, ANT2, ANT1, ANT3, 2,4-dinitrophenol, UCP2 


\section{FIGURES}

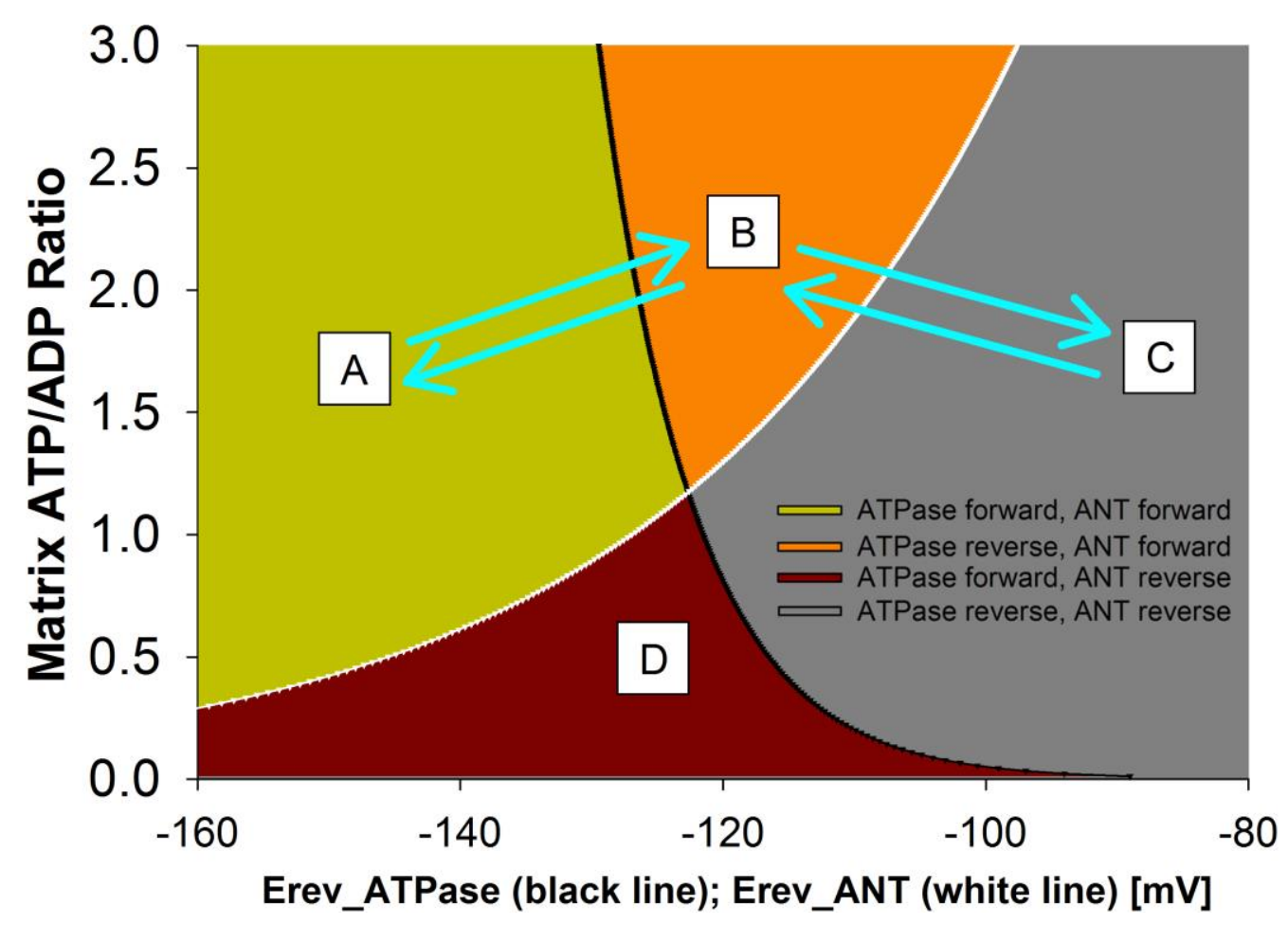

Figure $1[4,48,50]$; Computational estimations of $\mathrm{E}_{\text {rev_ATPase }}$ and $\mathrm{E}_{\text {rev_ANT }}(\mathrm{mV})$ at different mitochondrial matrix $[\mathrm{ATP}]_{\text {in }} /[\mathrm{ADP}]_{\text {in }}$ ratios. Black line is $\mathrm{E}_{\text {rev_ATPase, }}$, white line is $\mathrm{E}_{\text {rev_ANT. }}$. Note that a decreased $[\mathrm{ATP}]_{\text {in }} /[\mathrm{ADP}]_{\text {in }}$ ratio increases $\mathrm{E}_{\text {rev_ATPase }}$ and decreases $\mathrm{E}_{\text {rev_ANT. }} \mathrm{A}, \mathrm{B}$, $\mathrm{C}$ and D mark different operating states: (A) ATPase forward, ANT forward. (B) ATP reverse, ANT forward. (C) ATPase reverse, ANT reverse. (D) ATPase forward, ANT reverse. 

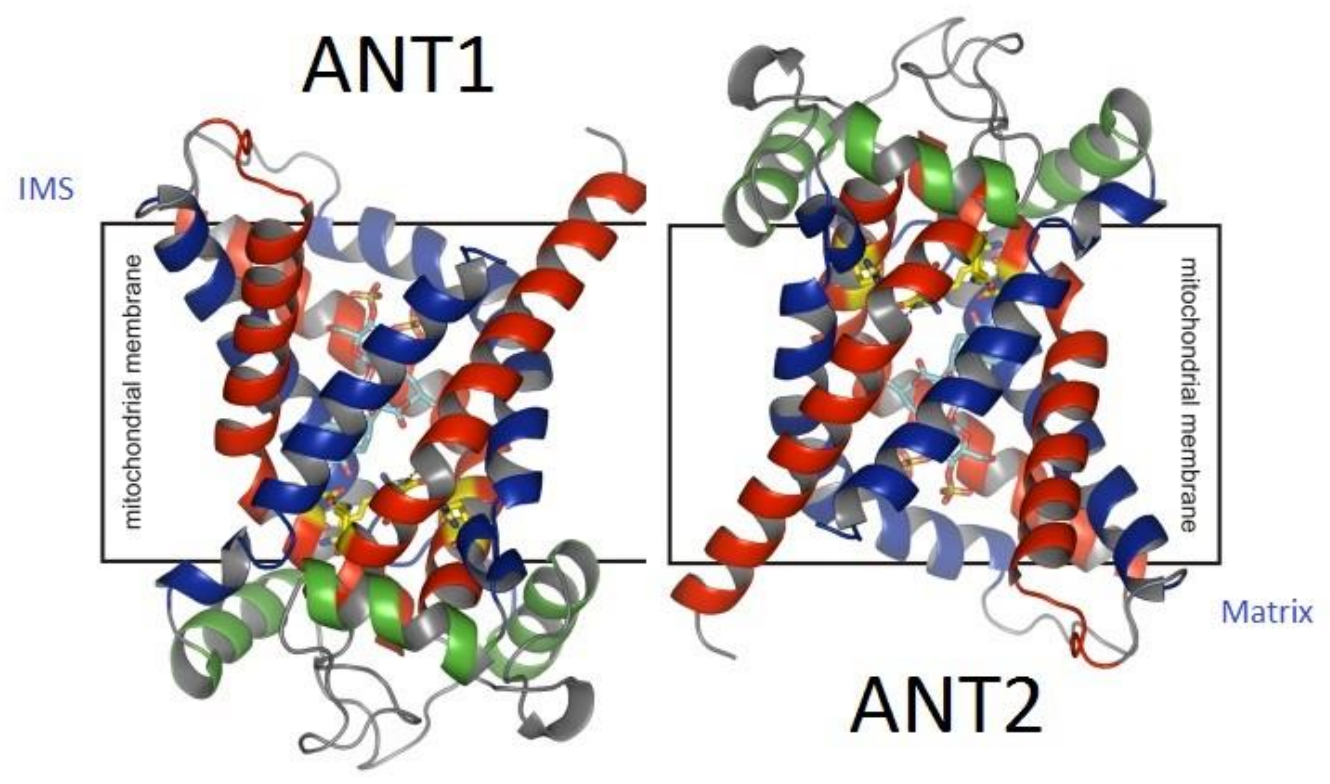

ANT2

Figure 2; Orientation of ANT1 [84] and the predicted, inverse orientation of ANT2. The mitochondrial intermembrane space (IMS) and matrix are labelled. 


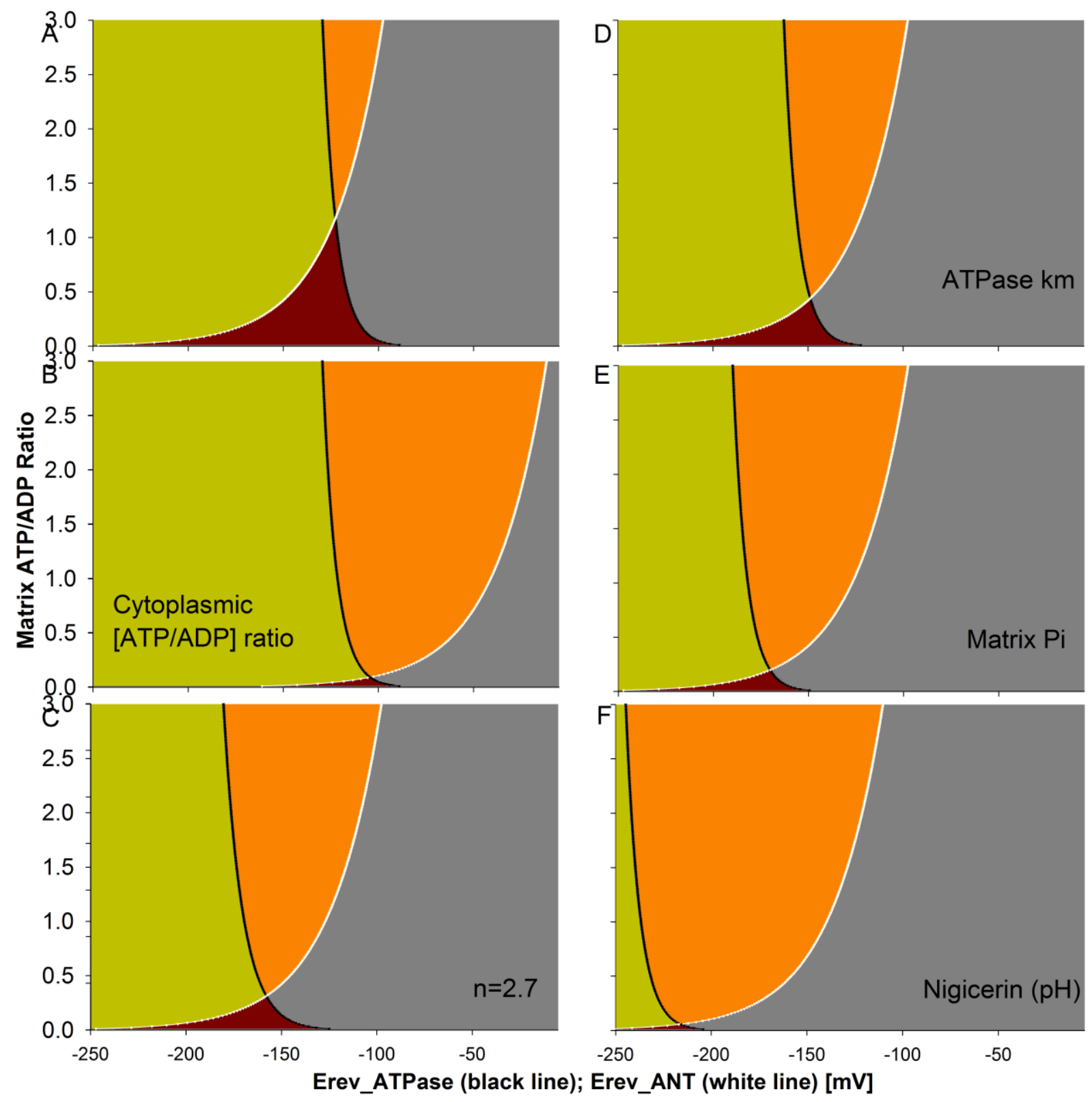

Figure 3; Computational estimations of $\mathrm{E}_{\text {rev_ATPase }}$ (black line) and $\mathrm{E}_{\text {rev_ANT }}$ (white line), which show their dependence on certain key parameters. (A) Same plots, using the same parameters, as Figure 1 (but shown with a different $\mathrm{X}$-axis range). (B) Cytoplasmic [ATP/ADP] ratio changed from 120 to 4.8. (C) ATPase coupling ratio, $n$, changed from 3.7 to 2.7. (D) ATPase affinity for ADP and ATP modified: $K_{w}$ changed from $10^{-3.198}$ to $10^{-1.599}, K_{q}$ from $10^{-4.06}$ to $10^{-6.09}$. (E) Matrix Pi level reduced from 10 to $0.01 \mathrm{mM}$. (F) Matrix $\mathrm{pH}$ decreased from 7.38 to 6.38 , intermembrane space $\mathrm{pH}$ increased from 7.25 to 8.25. This represents the action of the nigericin ionophore. 


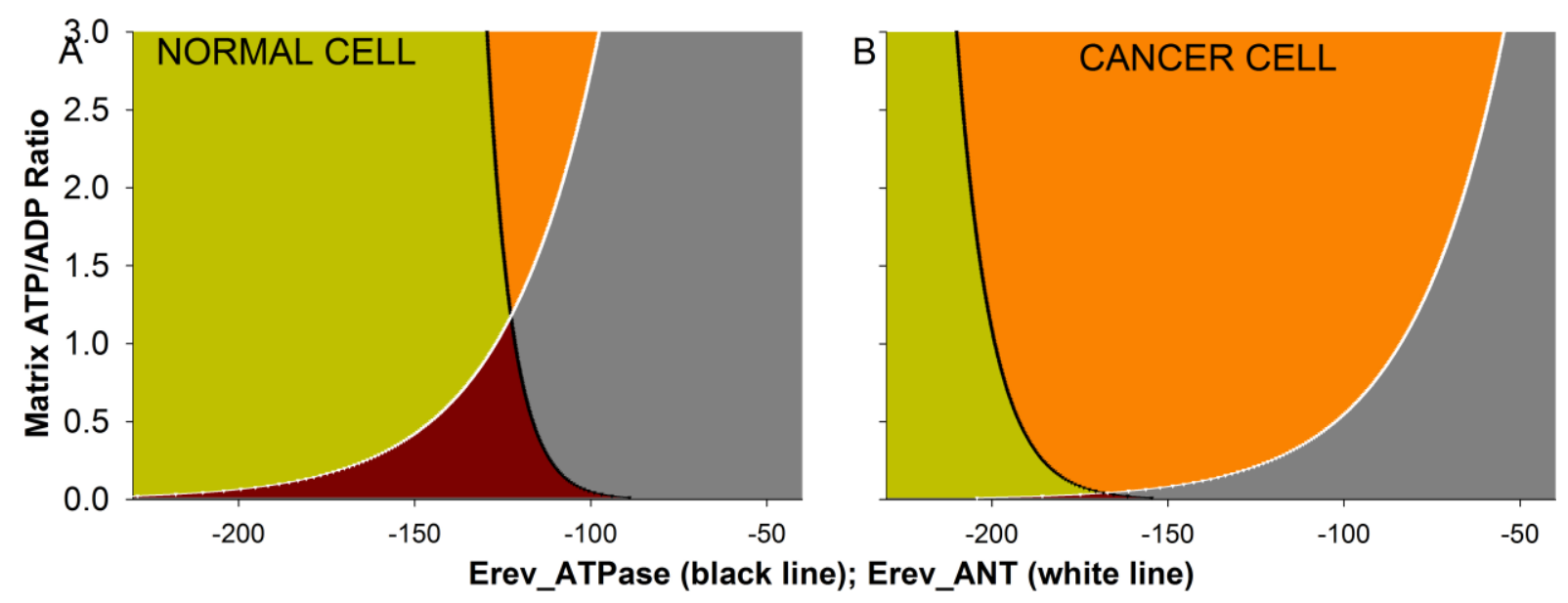

Figure 4; Computational estimations of $\mathrm{E}_{\text {rev_ATPase }}$ (black line) and $\mathrm{E}_{\text {rev_ANT }}$ (white line) for a normal cell (A) and a cancer cell (B). (A) Normal cell. Same plots, using the same parameters, as Figure 1 (but shown with a different $\mathrm{X}$-axis range). (B) Cancer cell. Cytoplasmic [ATP/ADP] ratio decreased from 120 to $24, \mathrm{H}^{+} / \mathrm{ATP}$ coupling ratio: $n=2.7$ instead of 3.7, matrix Pi reduced from 10 to $0.5 \mathrm{mM}$ and the matrix ATP/ADP ratio is doubled (if one reads the value on the $\mathrm{x}$-axis, to get the $\mathrm{E}_{\text {rev }}$ value, at $\mathrm{y}$-axis values: $\mathrm{y}=3$ for cancer panel and $\mathrm{y}=1.5$ for normal panel). $\mathrm{E}_{\text {rev_ANT }}=-115 \mathrm{mV}, \mathrm{E}_{\text {rev_ATP }}=-124 \mathrm{mV}$ for normal cell $(\mathrm{A})$; $\mathrm{E}_{\text {rev_ANT }}=-55 \mathrm{mV}, \mathrm{E}_{\text {rev_ATP }}=-211 \mathrm{mV}$ for cancer cell $(\mathrm{B})$.

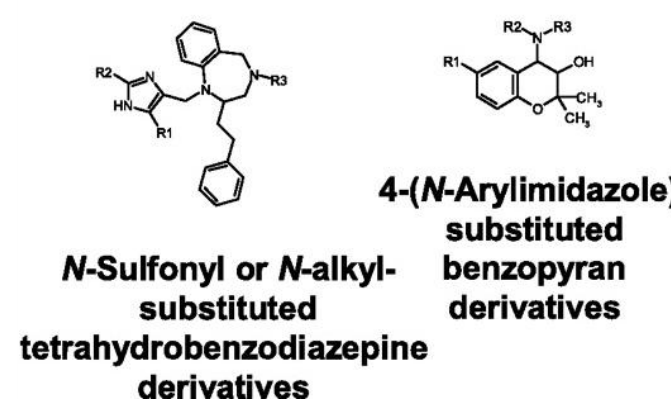

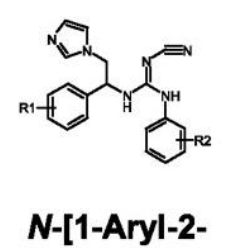

(1-imidazolo)ethyl]cyanoguanidine derivatives

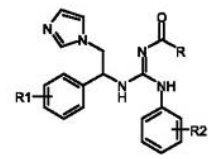

N-[1-Aryl-2-

(1-imidazolo)ethyl]acylguanidine derivatives

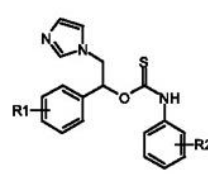

O-[1-Aryl-2-

(1-imidazolo)ethyl]thiourethane derivatives

Figure 5; The base structure of drugs that inhibit the reverse, ATP hydrolysing, but not the forward, ATP synthesising, operation of ATP synthase [144]. The R group is variable and some $\mathrm{R}$ groups are detailed in Table 1. 


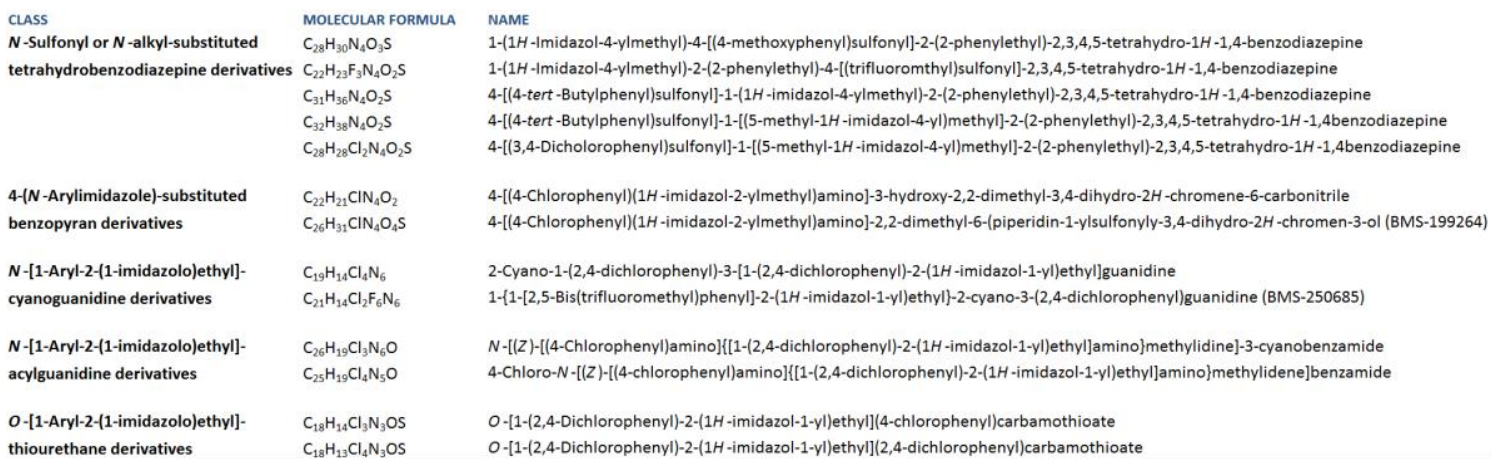

Table 1; A list of drugs that inhibit ATP hydrolysis, and not synthesis, by ATP synthase [144].

\section{REFERENCES}

[1] Stryer L, Berg JM, Tymoczko JL (2002) Biochemistry, $4^{\text {th }}$ Ed. New York, NY: WH Freeman.

[2] Alberts B, Johnson A, Lewis J, Raff M, Roberts K, Walter P (1994) Molecular Biology Of The Cell, $3^{\text {rd }}$ Ed. New York, NY: Garland Publishing.

[3] Nicholls DG, Ferguson S (2013) Bioenergetics. Academic Press.

[4] Chinopoulos C (2011) Mitochondrial consumption of cytosolic ATP: not so fast. FEBS letters 585(9):1255-1259.

[5] Zamzami N, Kroemer G (2001) The mitochondrion in apoptosis: how Pandora's box opens. Nat. Rev. Mol. Cell Biol. 2:67-71

[6] Bagkos G, Koufopoulos K, Piperi C (2014) A new model for mitochondrial membrane potential production and storage. Medical hypotheses 83(2):175-181.

[7] Bagkos G, Koufopoulos K, Piperi C (2014) ATP Synthesis Revisited: New Avenues for the Management of Mitochondrial Diseases. Current pharmaceutical design 20(28):45704579 .

[8] Bernal SD, Lampidis TJ, Summerhayes IA, Chen LB (1982) Rhodamine-123 selectively reduces clonal growth of carcinoma cells in vitro. Science 218(4577):1117-1119.

[9] Summerhayes IC, Lampidis TJ, Bernal SD, Nadakavukaren JJ, Nadakavukaren KK, Shepherd EL, Chen LB (1982) Unusual retention of rhodamine 123 by mitochondria in muscle and carcinoma cells. Proceedings of the National Academy of Sciences 79(17):52925296.

[10] Nadakavukaren KK, Nadakavukaren JJ, Chen LB (1985) Increased rhodamine 123 uptake by carcinoma cells. Cancer research 45(12 Part 1):6093-6099.

[11] Fantin VR, Berardi MJ, Scorrano L, Korsmeyer SJ, Leder P (2002) A novel mitochondriotoxic small molecule that selectively inhibits tumor cell growth. Cancer cell 2(1):29-42. 
[12] Modica-Napolitano JS, Aprille JR (2001) Delocalized lipophilic cations selectively target the mitochondria of carcinoma cells. Advanced drug delivery reviews 49(1):63-70.

[13] Davis S, Weiss MJ, Wong JR (1985) Mitochondrial and plasma membrane potentials cause unusual accumulation and retention of rhodamine 123 by human breast adenocarcinoma-derived MCF-7 cells. Journal of Biological Chemistry 260(25):1384413850.

[14] Houston MA, Augenlicht LH, Heerdt BG (2011) Stable differences in intrinsic mitochondrial membrane potential of tumor cell subpopulations reflect phenotypic heterogeneity. International journal of cell biology 2011.

[15] Heerdt BG, Houston MA, Augenlicht LH (2005) The intrinsic mitochondrial membrane potential of colonic carcinoma cells is linked to the probability of tumor progression. Cancer Res 65:9861-9867.

[16] Heerdt BG, Houston MA, Augenlicht LH. Growth properties of colonic tumor cells are a function of the intrinsic mitochondrial membrane potential. Cancer Res 2006;66(3):1591-6.

[17] Chen LB (1988) Mitochondrial membrane potential in living cells. Annual review of cell biology 4(1):155-181.

[18] Fantin VR, St-Pierre J, Leder P (2006) Attenuation of LDH-A expression uncovers a link between glycolysis, mitochondrial physiology, and tumor maintenance. Cancer cell $9(6): 425-434$.

[19] Bonnet S, Archer SL, Allalunis-Turner J, Haromy A, Beaulieu C et al. (2007) A mitochondria- $\mathrm{K}+$ channel axis is suppressed in cancer and its normalization promotes apoptosis and inhibits cancer growth. Cancer cell 11(1):37-51.

[20] Warburg O (1956) On the origin of cancer cells. Science 123(3191):309-314.

[21] Ferreira LM (2010) Cancer metabolism: the Warburg effect today. Exp Mol Pathol 89(3):372-380.

[22] Kim JW, Dang CV (2006) Cancer's molecular sweet tooth and the Warburg effect. Cancer Res 66(18):8927-8930.

[23] Lopez-Lazaro M (2008) The warburg effect: why and how do cancer cells activate glycolysis in the presence of oxygen? Anti-Cancer Agent Me 8(3):305-312.

[24] Elliott RL, Jiang XP, Head JF (2014) Want to Cure Cancer? Then Revisit the Past; "Warburg Was Correct", Cancer Is a Metabolic Disease. Journal of Cancer Therapy

[25] Gatenby RA, Gillies RJ (2004) Why do cancers have high aerobic glycolysis? Nat Rev Cancer 4(11):891-899.

[26] Bui T, Thompson CB (2006) Cancer's sweet tooth. Cancer cell 9(6):419-420.

[27] Nakashima RA, Paggi MG, Pedersen PL (1984) Contributions of glycolysis and oxidative phosphorylation to adenosine 5 '-triphosphate production in AS-30D hepatoma cells. Cancer Res 44(12 Part 1):5702-5706. 
[28] Diaz-Ruiz R, Rigoulet M, Devin A (2011) The Warburg and Crabtree effects: On the origin of cancer cell energy metabolism and of yeast glucose repression. BBA-Bioenergetics 1807(6):568-576.

[29] DeBerardinis RJ, Lum JJ, Hatzivassiliou G, Thompson CB (2008) The biology of cancer: metabolic reprogramming fuels cell growth and proliferation. Cell metabolism, $7(1): 11-20$.

[30] Mathupala SP, Ko YH, Pedersen PL (2010) The pivotal roles of mitochondria in cancer: Warburg and beyond and encouraging prospects for effective therapies. Biochimica et Biophysica Acta (BBA)-Bioenergetics 1797(6):1225-1230.

[31] Vander Heiden MG, Cantley LC, Thompson CB (2009) Understanding the Warburg effect: the metabolic requirements of cell proliferation. Science 324(5930):1029-1033.

[32] Czernin J, Phelps ME (2002) Positron emission tomography scanning: current and future applications. Annu Rev Med 53:89-112.

[33] Gambhir SS, Czernin J, Schwimmer J, Silverman DH, Coleman RE, Phelps MEA (2001) Tabulated summary of the FDG PET literature. J Nucl Med 42:1S-93S.

[34] Forrest MD (2015) NADH as a cancer medicine. bioRxiv:019307.

[35] Birsoy K, Possemato R, Lorbeer FK, Bayraktar EC, Thiru P et al. (2014) Metabolic determinants of cancer cell sensitivity to glucose limitation and biguanides. Nature 508(7494):108-112.

[36] Moreno-Sánchez R, Rodríguez-Enríquez S, Saavedra E, Marín-Hernández A, Gallardo-Pérez JC (2009) The bioenergetics of cancer: is glycolysis the main ATP supplier in all tumor cells? Biofactors 35(2): 209-225.

[37] Wadhwa R, Sugihara T, Yoshida A, Nomura H, Reddel RR, et al. (2000) Selective toxicity of MKT-077 to cancer cells is mediated by its binding to the hsp70 family protein mot-2 and reactivation of p53 function. Cancer Res 60:6818-6821.

[38] Schulz TJ, Thierbach R, Voigt A, et al (2006) Induction of oxidative metabolism by mitochondrial frataxin inhibits cancer growth: Otto Warburg revisited. J Biol Chem 281:97781 .

[39] Christofk HR, Vander Heiden MG, Harris MH, Ramanathan A, Gerszten RE, Wei R, ... \& Cantley LC (2008) The M2 splice isoform of pyruvate kinase is important for cancer metabolism and tumour growth. Nature 452(7184):230-233.

[40] Propper DJ, Braybrooke JP, Taylor DJ, Lodi R, Styles P, Cramer JA, ... \& Harris AL (1999) Phase I trial of the selective mitochondrial toxin MKT 077 in chemo-resistant solid tumours. Annals of oncology 10(8):923-927.

[41] Britten CD, Rowinsky EK, Baker SD, Weiss GR, Smith L, Stephenson J, ... \& Eckhardt SG (2000) A phase I and pharmacokinetic study of the mitochondrial-specific rhodacyanine dye analog MKT 077. Clinical cancer research 6(1):42-49. 
[42] Ross MF, Da Ros T, Blaikie FH, Prime TA, Porteous CM, Severina II, Skulachev VP, Kjaergaard HG, Smith RA, Murphy MP (2006) Accumulation of lipophilic dications by mitochondria and cells. Biochem. J. 400:199-208.

[43] Koya K, Li Y, Wang H, Ukai T, Tatsuta N, Kawakami M, ... Chen LB (1996) MKT-077, a novel rhodacyanine dye in clinical trials, exhibits anticarcinoma activity in preclinical studies based on selective mitochondrial accumulation. Cancer research 56(3):538-543.

[44] Weiss MJ, Wong JR, Ha CS, Bleday R, Salem RR, Steele GD, Chen LB (1987)

Dequalinium, a topical antimicrobial agent, displays anticarcinoma activity based on selective mitochondrial accumulation. Proceedings of the National Academy of Sciences 84(15):54445448.

[45] Sun X, Wong JR, Song K, Hu J, Garlid KD, Chen LB (1994) AA1, a newly synthesized monovalent lipophilic cation, expresses potent in vivo antitumor activity. Cancer research 54(6):1465-1471.

[46] Modica-Napolitano JS, Weiss MJ, Chen LB, Aprille JR (1984) Rhodamine 123 inhibits bioenergetic function in isolated rat liver mitochondria. Biochemical and biophysical research communications 118(3):717-723.

[47] Chiba Y, Kubota T, Watanabe M, Matsuzaki SW, Otani Y, Teramoto T, ... \& Kitajima M (1997) MKT-077, localized lipophilic cation: antitumor activity against human tumor xenografts serially transplanted into nude mice. Anticancer research 18(2A):1047-1052.

[48] Chinopoulos C, Gerencser AA, Mandi M, Mathe K, Torocsik B, Doczi J, Turiak L, Kiss G, Konrad C, Vajda S, Vereczki V, Oh RJ, Adam-Vizi V (2010) Forward operation of adenine nucleotide translocase during F0F1-ATPase reversal: critical role of matrix substratelevel phosphorylation. FASEB J 24:2405-2416.

[49] Chinopoulos C, Adam-Vizi V (2010) Mitochondria as ATP consumers in cellular pathology. Biochim Biophys Acta 1802:221-227.

[50] Chinopoulos C (2011) The "B Space”" of mitochondrial phosphorylation. Journal of Neuroscience Research 89:1897-1904.

[51] Watt IN, Montgomery MG, Runswick MJ, Leslie AG, Walker JE (2010) Bioenergetic cost of making an adenosine triphosphate molecule in animal mitochondria. Proceedings of the National Academy of Sciences 107(39):16823-16827.

[52] Clémençon B, Babot M, Trézéguet V (2013) The mitochondrial ADP/ATP carrier (SLC25 family): Pathological implications of its dysfunction. Molecular aspects of medicine 34(2):485-493.

[53] Chevrollier A, Loiseau D, Chabi B, Renier G, Douay O, Malthièry Y, Stepien G (2005) ANT2 isoform required for cancer cell glycolysis. Journal of bioenergetics and biomembranes 37(5):307-317.

[54] Chevrollier A, Loiseau D, Reynier P, Stepien G (2011) Adenine nucleotide translocase 2 is a key mitochondrial protein in cancer metabolism. Biochimica et Biophysica Acta (BBA)Bioenergetics 1807(6):562-567. 
[55] Maldonado EN, Lemasters JJ (2014) ATP/ADP ratio, the missed connection between mitochondria and the Warburg effect. Mitochondrion 19:78-84.

[56] Maldonado EN, Vuicich J, DeHart DN, Rodebaugh HS, Lemasters JJ (2013)

Translocation of glycolytic ATP into mitochondria of cancer cells does not utilize the adenine nucleotide transporter. Biophys J 104:303a-304a.

[57] Tewari SG, Dash RK, Beard DA, Bazil JN (2012) A Biophysical Model of the Mitochondrial ATP-Mg/Pi Carrier. Biophysical journal 103(7):1616-1625.

[58] TTraba J, Froschauer EM, Wiesenberger G, Satrústegui J, Del Arco A (2008) Yeast mitochondria import ATP through the calcium-dependent ATP-Mg/Pi carrier Sal1p, and are ATP consumers during aerobic growth in glucose. Molecular microbiology 69(3):570-585.

[59] Schmitz-Esser S, Linka N, Collingro A, Beier CL, Neuhaus HE, Wagner M, Horn M (2004) ATP/ADP translocases: a common feature of obligate intracellular amoebal symbionts related to Chlamydiae and Rickettsiae. J Bacteriol 186(3):683-691.

[60] Audia JP, Winkler HH (2006) Study of the five Rickettsia prowazekii proteins annotated as ATP/ADP translocases (Tlc): only Tlc1 transports ATP/ADP, while Tlc4 and Tlc5 transport other ribonucleotides. J Bacteriol 188(17):6261-6268.

[61] Trentmann O, Horn M, van Scheltinga ACT, Neuhaus HE, Haferkamp I (2007) Enlightening Energy Parasitism by Analysis of an ATP/ADP Transporter from Chlamydiae. PLoS Biol 5(9):e231. doi:10.1371/journal.pbio.0050231.

[62] Schmitz-Esser S, Haferkamp I, Knab S, Penz T, Ast M, Kohl C, et al. (2008) Lawsonia intracellularis contains a gene encoding a functional rickettsia-like ATP/ADP translocase for host exploitation. J Bacteriol 190(17):5746-5752.

[63] Trentmann O, Jung B, Neuhaus HE, Haferkamp I (2008) Nonmitochondrial ATP/ADP transporters accept phosphate as third substrate. J Biol Chem 283(52):36486-36493.

[64] Altschul SF, Gish W, Miller W, Myers EW, Lipman DJ (1990) Basic local alignment search tool. Journal of molecular biology 215(3):403-410.

[65] Tsaousis AD, Kunji ER, Goldberg AV, Lucocq JM, Hirt RP, Embley TM (2008) A novel route for ATP acquisition by the remnant mitochondria of Encephalitozoon cuniculi. Nature 453(7194):553-556.

[66] Kunji ER (2004) The role and structure of mitochondrial carriers. FEBS letters 564(3):239-244.

[67] Alves S (2008) Two of a kind. Nature Reports Stem Cells.

[68] Baker M (2008) Cancer and embryonic stem cells share genetic fingerprints. Nature Reports Stem Cells.

[69] Chung S, Dzeja PP, Faustino RS, Perez-Terzic C, Behfar A, Terzic A (2007)

Mitochondrial oxidative metabolism is required for the cardiac differentiation of stem cells. Nat Clin Pract Cardiovasc Med 4: S60 - S67. 
[70] Teslaa T, Teitell MA (2014) Pluripotent stem cell energy metabolism: an update. The EMBO journal e201490446.

[71] Zalzman M, Falco G, Sharova LV, Nishiyama A, Thomas M, Lee SL, ... \& Ko MS (2010) Zscan4 regulates telomere elongation and genomic stability in ES cells. Nature 464(7290):858-863.

[72] Hayflick L (1997) Mortality and immortality at the cellular level. A review.Biochemistry-New York-English Translation of Biokhimiya 62(11):1180-1190.

[73] Kondoh H, Lleonart ME, Bernard D, Gil J (2007) Protection from oxidative stress by enhanced glycolysis; a possible mechanism of cellular immortalization. Histology and histopathology 22(1): 85-90.

[74] Hong Y, Stambrook PJ (2004) Restoration of an absent G1 arrest and protection from apoptosis in embryonic stem cells after ionizing radiation. PNAS 101(40):14443-14448.

[75] Kokoszka JE, Waymire KG, Levy SE, Sligh JE, Cai J, Jones DP, MacGregor GR, Wallace DC (2004) The ADP/ATP translocator is not essential for the mitochondrial permeability transition pore. Nature 427:461-465.

[76] Jang JY, Choi Y, Jeon YK, Kim CW (2008) Suppression of adenine nucleotide translocase-2 by vector-based siRNA in human breast cancer cells induces apoptosis and inhibits tumor growth in vitro and in vivo. Breast Cancer Res 10(1):R11.

[77] Le Bras M, Borgne-Sanchez A, Touat Z, El Dein OS, Deniaud A, Maillier E, Lecellier G, Rebouillat D, Lemair C, Kroemer G, Jacotot E, Brenner C (2006) Chemosensitization by knockdown of adenine nucleotide translocase-2. Cancer Res 66:9143-9152.

[78] Jang JY, Choi Y, Jeon YK, Aung KC, Kim CW (2008) Over-expression of adenine nucleotide translocase 1 (ANT1) induces apoptosis and tumor regression in vivo. BMC cancer 8(1): 160 .

[79] Zamora M, Granell M, Mampel T, Vinas O (2004) Adenine nucleotide translocase 3 (ANT3) overexpression induces apoptosis in cultured cells. FEBS Lett 563:155-160.

[80] Bauer MK, Schubert A, Rocks O, Grimm S (1999) Adenine nucleotide translocase-1, a component of the permeability transition pore, can dominantly induce apoptosis. The Journal of cell biology 147(7):1493-1502.

[81] Klingenberg M (2008) The ADP and ATP transport in mitochondria and its carrier. Biochimica et Biophysica Acta (BBA)-Biomembranes 1778(10):1978-2021.

[82] De Marcos Lousa C, Trézéguet V, Dianoux AC, Brandolin G, Lauquin GJM (2002) The human mitochondrial ADP/ATP carriers: kinetic properties and biogenesis of wild-type and mutant proteins in yeast $S$. cerevisiae. Biochemistry 41:14412-14420.

[83] Dahout-Gonzalez C, Nury H, Trezeguet V, Lauquin GJ, Pebay-Peyroula E, Brandolin G (2006) Molecular, functional, and pathological aspects of the mitochondrial ADP/ATP carrier. Physiology (Bethesda) 21:242-249. 
[84] Pebay-Peyroula E, Dahout-Gonzalez C, Kahn R, Trezeguet V, Lauquin GJ, Brandolin G (2003) Structure of mitochondrial ADP/ATP carrier in complex with carboxyatractyloside. Nature 426:39-44.

[85] Dong GC, Chuang PH, Forrest MD, Lin YC, Chen HM (2006) Immuno-suppressive effect of blocking the CD28 signaling pathway in T-cells by an active component of Echinacea found by a novel pharmaceutical screening method. Journal of medicinal chemistry 49(6):1845-1854.

[86] Lunt SY, Vander Heiden MG (2011) Aerobic glycolysis: meeting the metabolic requirements of cell proliferation. Annu Rev Cell Dev Bi 27:441-464.

[87] Ganapathy-Kanniappan S, Geschwind JF (2013) Tumor glycolysis as a target for cancer therapy: progress and prospects. Mol Cancer 12(152):4598-12.

[88] Vinogradov AD (2000) Steady-state and pre-steady state kinetics of mitochondrial F1F0 ATPase: is ATP synthase a reversible molecular machine. Journal of Experimental Biology 203:41-9.

[89] Klingenberg M (1977) The Adenine-Nucleotide Exchange in Submitochondrial (Sonic) Particles. European Journal of Biochemistry 76.2:553-565.

[90] Israelsen WJ, Vander Heiden MG (2010) ATP consumption promotes cancer metabolism. Cell 143(5):669-671.

[91] Shabalina IG, Kramarova TV, Nedergaard J, Cannon B (2006) Carboxyatractyloside effects on brown-fat mitochondria imply that the adenine nucleotide translocator isoforms ANT1 and ANT2 may be responsible for basal and fatty-acid-induced uncoupling respectively. Biochem J 399:405-414.

[92] Brand MD, Pakay JL, Ocloo A, Kokoszka J, Wallace DC, Brookes PS, Cornwall EJ (2005) The basal proton conductance of mitochondria depends on adenine nucleotide translocase content. Biochem J 392:353-362

[93] Brand MD, Pakay JL, Ocloo A, Kokozka J, Wallace DC, Brookes PS, Cornwall EJ (2005) The basal proton conductance of mitochondria depends on adenine nucleotide translocase content. Biochemical Journal 392(2):353-362.

[94] Lena A, Rechichi M, Salvetti A, Vecchio D, Evangelista M, Rainaldi G, Gremigni V, Rossi L (2010) The silencing of adenine nucleotide translocase isoform 1 induces oxidative stress and programmed cell death in ADF human glioblastoma cells. FEBS journal 277(13):2853-2867.

[95] Brand MD (2000) Uncoupling to survive? The role of mitochondrial inefficiency in ageing. Exp Gerontol 35:811-820.

[96] Echtay KS, Roussel D, St-Pierre J, Jekabsons MB, Cadenas S, Stuart JA, Brand MD (2002) Superoxide activates mitochondrial uncoupling proteins. Nature 415(6867):96-99.

[97] Yu Q, Heikal AA (2009) Two-photon autofluorescence dynamics imaging reveals sensitivity of intracellular NADH concentration and conformation to cell physiology at the single-cell level. Journal of Photochemistry and Photobiology B: Biology 95(1):46-57. 
[98] Blacker TS, Mann ZF, Gale JE, Ziegler M, Bain AJ, Szabadkai G, Duchen MR (2014) Separating NADH and NADPH fluorescence in live cells and tissues using FLIM. Nature communications 5 .

[99] Feeney R, Clarke AR, Holbrook JJ (1990) A single amino acid substitution in lactate dehydrogenase improves the catalytic efficiency with an alternative coenzyme. Biochemical and biophysical research communications 166(2):667-672.

[100] Valle A, Oliver J, Roca P (2010) Role of uncoupling proteins in cancer. Cancers 2(2):567-591.

[101] Donadelli M, Dando I, Dalla Pozza E, Palmieri M (2015) Mitochondrial uncoupling protein 2 and pancreatic cancer: A new potential target therapy. World journal of gastroenterology: WJG 21(11):3232.

[102] Ayyasamy V, Owens KM, Desouki MM, Liang P, Bakin A, Thangaraj K, et al. (2011) Cellular Model of Warburg Effect Identifies Tumor Promoting Function of UCP2 in Breast Cancer and Its Suppression by Genipin. PLoS ONE 6(9):e24792.

doi:10.1371/journal.pone.0024792.

[103] Vozza A, Parisi G, De Leonardis F, Lasorsa FM, Castegna A, Amorese D, Marmo R, Calcagnile VM, Palmieri L, Ricquier D, Paradies E, Scarcia P, Palmieri F, Bouillaud F, Fiermonte G (2014) UCP2 transports C4 metabolites out of mitochondria, regulating glucose and glutamine oxidation. Proc Natl Acad Sci USA 111:960-965.

[104] Deng S, Yang Y, Han Y, Li X, Wang X, Li X, et al. (2012) UCP2 Inhibits ROSMediated Apoptosis in A549 under Hypoxic Conditions. PLoS ONE 7(1): e30714.

[105] Derdak Z, Mark NM, Beldi G, Robson SC, Wands JR, Baffy G (2008) The mitochondrial uncoupling protein-2 promotes chemoresistance in cancer cells. Cancer research 68(8):2813-2819

[106] Mailloux RJ, Adjeitey CN-K, Harper M-E (2010) Genipin-Induced Inhibition of Uncoupling Protein-2 Sensitizes Drug-Resistant Cancer Cells to Cytotoxic Agents. PLoS ONE 5(10):e13289

[107] Hong HY, Kim BC (2007) Mixed lineage kinase 3 connects reactive oxygen species to c-Jun NH2-terminal kinase-induced mitochondrial apoptosis in genipin-treated PC3 human prostate cancer cells. Biochem. Biophys. Res. Commun. 362:307-312.

[108] Kim BC, Kim HG, Lee SA, Lim S, Park EH, Kim SJ, Lim CJ (2005) Genipin-induced apoptosis in hepatoma cells is mediated by reactive oxygen species/c-Jun NH2-terminal kinasedependent activation of mitochondrial pathway. Biochem. Pharmacol. 70:1398-1407.

[109] Baffy G (2010) Uncoupling protein-2 and cancer. Mitochondrion 10:243-252

[110] Zhang J, et al. (2011) UCP2 regulates energy metabolism and differentiation potential of human pluripotent stem cells. EMBO J 30(24):4860-4873.

[111] Samudio I, Fiegl M, McQueen T, Clise-Dwyer K, Andreeff M (2008) The warburg effect in leukemia-stroma cocultures is mediated by mitochondrial uncoupling associated with uncoupling protein 2 activation. Cancer Res 68:5198-5205. 
[112] Santandreu FM, Roca P, Oliver J (2010) Uncoupling protein-2 knockdown mediates the cytotoxic effects of cisplatin. Free Radical Biology and Medicine 49(4):658-666.

[113] Nicholls DG (2006) Simultaneous monitoring of ionophore-and inhibitor-mediated plasma and mitochondrial membrane potential changes in cultured neurons. Journal of Biological Chemistry 281(21):14864-14874.

[114] Akhmedov D, Braun M, Mataki C, Park KS, Pozzan T, Schoonjans K, ... \& Wiederkehr A (2010) Mitochondrial matrix $\mathrm{pH}$ controls oxidative phosphorylation and metabolismsecretion coupling in INS-1E clonal $\beta$ cells. The FASEB Journal 24(11):4613-4626.

[115] Deng CC, Liang Y, Wu MS, Feng FT, Hu WR, Chen LZ, ... \& Zeng YX (2013)

Nigericin selectively targets cancer stem cells in nasopharyngeal carcinoma. The international journal of biochemistry \& cell biology 45(9):1997-2006.

[116] Miyake H, Hara I, Yamanaka K, Arakawa S, Kamidono S (1999) Calcium ionophore, ionomycin inhibits growth of human bladder cancer cells both in vitro and in vivo with alteration of Bcl-2 and Bax expression levels. The Journal of urology 162(3):916-921.

[117] Rokitskaya TI, Ilyasova TM, Severina II, Antonenko YN, Skulachev VP (2013) Electrogenic proton transport across lipid bilayer membranes mediated by cationic derivatives of rhodamine 19: comparison with anionic protonophores. European Biophysics Journal 42(6):477-485.

[118] Casey JR, Grinstein S, Orlowski J (2010) Sensors and regulators of intracellular pH. Nature reviews Molecular cell biology 11(1):50-61.

[119] Davies KM, Strauss M, Daum B, Kief JH, Osiewacz HD, Rycovska A, ... Kühlbrandt W (2011) Macromolecular organization of ATP synthase and complex I in whole mitochondria. Proceedings of the National Academy of Sciences 108(34):14121-14126.

[120] Damaghi M, Wojtkowiak JW, Gillies RJ (2013) pH sensing and regulation in cancer. Frontiers in physiology 4.

[121] Gerweck LE, Seetharaman K (1996) Cellular pH gradient in tumor versus normal tissue: potential exploitation for the treatment of cancer. Cancer Res. 56:119-1198.

[122] Gerweck LE, Vijayappa S, Kozin S (2006) Tumor pH controls the in vivo efficacy of weak acid and base chemotherapeutics. Mol. Cancer Ther. 5:1275-1279.

[123] McCarty MF, Whitaker J (2010) Manipulating tumor acidification as a cancer treatment strategy. Altern Med Rev 15(3):264-72.

[124] Han YH, Kim SW, Kim SH, Kim SZ, Park WH (2008) 2,4-Dinitrophenol induces G1 phase arrest and apoptosis in human pulmonary adenocarcinoma Calu-6 cells. Toxicology in Vitro 22(3):659-670.

[125] Han YH, Yang YM, Park WH (2010) Carbonyl Cyanide P-(Trifluoromethoxy) Phenylhydroazone Induces Caspase-independent Apoptosis in As4. 1 Juxtaglomerular Cells. Anticancer research 30(7):2863-2868. 
[126] Datta S, Li J, Mahdi F, Jekabsons MB, Nagle DG, Zhou YD (2012) Glycolysis inhibitor screening identifies the bis-geranylacylphloroglucinol protonophore moronone from Moronobea coccinea. Journal of natural products 75(12):2216-2222.

[127] Newell KJ, Tannock IF (1989) Reduction of intracellular pH as a possible mechanism for killing cells in acidic regions of solid tumors: effects of carbonylcyanide3chlorophenylhydrazone. Cancer Res. 49:4477-4482.

[128] Reis FH, Pardo-Andreu GL, Nuñez-Figueredo Y, Cuesta-Rubio O, Marín-Prida J, Uyemura SA, ... Alberici LC (2014) Clusianone, a naturally occurring nemorosone regioisomer, uncouples rat liver mitochondria and induces HepG2 cell death. Chemicobiological interactions 212:20-29.

[129] Hostanska K, Reichling J, Bommer S, Weber M, Saller R (2003) Hyperforin a constituent of St John's wort (Hypericum perforatum L.) extract induces apoptosis by triggering activation of caspases and with hypericin synergistically exerts cytotoxicity towards human malignant cell lines. Eur. J. Pharm. Biopharm. 56:121-132.

[130] Pardo-Andreu GL, Nuñez-Figueredo Y, Tudella VG, Cuesta-Rubio O, Rodrigues FP, Pestana CR, ... Curti C (2011) The anti-cancer agent nemorosone is a new potent protonophoric mitochondrial uncoupler. Mitochondrion 11(2):255-263.

[131] Jara JA, Castro-Castillo V, Saavedra-Olavarría J, Peredo L, Pavanni M, Jaña F, ... \& Ferreira J (2014) Antiproliferative and uncoupling effects of delocalized, lipophilic, cationic gallic acid derivatives on cancer cell lines. Validation in vivo in singenic mice. Journal of medicinal chemistry 57(6):2440-2454.

[132] Ryoo IJ, Park HR, Choo SJ, Hwang JH, Park YM, Bae KH, ... Yoo ID (2006) Selective cytotoxic activity of valinomycin against HT-29 human colon carcinoma cells via downregulation of GRP78. Biological and Pharmaceutical Bulletin 29(4):817-820.

[133] Ruiz-Marcial C, Chilpa RR, Estrada E, Reyes-Esparza J, Fariña GG, RodriguezFragoso L (2007) Antiproliferative, cytotoxic and antitumour activity of coumarins isolated from Calophyllum brasiliense. Journal of pharmacy and pharmacology 59(5):719-726.

[134] Brenzan MA, Santos AO, Nakamura CV, Dias Filho BP, Ueda-Nakamura T, Young MCM, Correa G, Junior JA, Morgado-Diaz A, Cortez DAG (2012) Effects of (-) mammea $\mathrm{A} / \mathrm{BB}$ isolated from Calophyllum brasiliense leaves and derivatives on mitochondrial membrane of Leishmania amazonensis. Phytomedicine 19(3):223-230.

[135] Du L, Mahdi F, Jekabsons MB, Nagle DG, Zhou YD (2010) Mammea E/BB, an isoprenylated dihydroxycoumarin protonophore that potently uncouples mitochondrial electron transport, disrupts hypoxic signaling in tumor cells. Journal of natural products 73(11):1868-1872.

[136] Lou P, Hansen B, Olsen P, Tullin S, Murphy M, Brand M (2007) Mitochondrial uncouplers with an extraordinary dynamic range. Biochem. J 407:129-140.

[137] Terada H (1990) Uncouplers of oxidative phosphorylation. Environmental Health Perspectives 87:213. 
[138] Goldgof M, Xiao C, Chanturiya T, Jou W, Gavrilova O, Reitman ML (2014) The chemical uncoupler 2, 4-dinitrophenol (DNP) protects against diet-induced obesity and improves energy homeostasis in mice at thermoneutrality. Journal of Biological Chemistry 289(28):19341-19350.

[139] Grundlingh J, Dargan PI, El-Zanfaly M, Wood DM (2011) 2, 4-dinitrophenol (DNP): a weight loss agent with significant acute toxicity and risk of death. Journal of Medical Toxicology 7(3):205-212.

[140] Horner WD (1941) A study of dinitrophenol and its relation to cataract formation. Transactions of the American Ophthalmological Society 39:405.

[141] Harper JA, Dickinson K, Brand MD (2001) Mitochondrial uncoupling as a target for drug development for the treatment of obesity. Obesity Reviews 2(4):255-265.

[142] Cerqueira FM, Laurindo FRM, Kowaltowski AJ (2011) Mild Mitochondrial Uncoupling and Calorie Restriction Increase Fasting eNOS, Akt and Mitochondrial Biogenesis. PLoS ONE 6(3):e18433

[143] Antonenko YN, Khailova LS, Knorre DA, Markova OV, Rokitskaya TI, Ilyasova TM, et al. (2013) Penetrating Cations Enhance Uncoupling Activity of Anionic Protonophores in Mitochondria. PLoS ONE 8(4):e61902.

[144] Hong S, Pedersen PL (2008) ATP synthase and the actions of inhibitors utilized to study its roles in human health, disease, and other scientific areas. Microbiology and Molecular Biology Reviews 72(4):590-641.

[145] Ma Z, Cao M, Liu Y, He Y, Wang Y, Yang C, ... \& Gao F (2010) Mitochondrial F1FoATP synthase translocates to cell surface in hepatocytes and has high activity in tumor-like acidic and hypoxic environment. Acta biochimica et biophysica Sinica 42(8):530-537.

[146] Huang CY, Huang HY, Forrest MD, Pan YR, Wu WJ, Chen HM (2014) Inhibition Effect of a Custom Peptide on Lung Tumors. PloS ONE 9(10):e109174.

[147] Grover GJ, Marone PA, Koetzner L, Seto-Young D (2008) Energetic signalling in the control of mitochondrial F 1 F 0 ATP synthase activity in health and disease. The international journal of biochemistry \& cell biology 40(12):2698-2701.

[148] Grover GJ, Malm J (2008) Pharmacological Profile of the Selective Mitochondrial F1F0 ATP Hydrolase Inhibitor BMS-199264 in Myocardial Ischemia. Cardiovascular therapeutics 26(4):287-296.

[149] Grover GJ, Atwal KS, Sleph PG, Wang FL, Monshizadegan H, Monticello T, Green DW (2004) Excessive ATP hydrolysis in ischemic myocardium by mitochondrial F1F0ATPase: effect of selective pharmacological inhibition of mitochondrial ATPase hydrolase activity. American Journal of Physiology-Heart and Circulatory Physiology 287(4):H1747H1755.

[150] Ivanes F, Faccenda D, Gatliff J, Ahmed AA, Cocco S, Cheng CHK, ... \& Campanella M (2014) The compound BTB06584 is an IF1-dependent selective inhibitor of the mitochondrial F1Fo-ATPase. British journal of pharmacology 171(18):4193-4206. 
[151] Song CC, Lu X, Cheng BB, Du J, Li B, Ling CQ (2007) Effects of melittin on growth and angiogenesis of human hepatocellular carcinoma BEL-7402 cell xenografts in nude mice. Chinese journal of cancer 26(12):1315-1322.

[152] Pathak RK, Marrache S, Harn DA, Dhar S (2014) Mito-DCA: a mitochondria targeted molecular scaffold for efficacious delivery of metabolic modulator dichloroacetate. ACS chemical biology 9(5):1178-1187.

[153] Blaikie F, Brown S, Samuelsson L, Brand M, Smith R, Murphy M (2006) Targeting dinitrophenol to mitochondria: limitations to the development of a self-limiting mitochondrial protonophore. Bioscience reports 26:231-243.

[154] Apostolova N, Victor VM (2015) Molecular Strategies for Targeting Antioxidants to Mitochondria: Therapeutic Implications. Antioxidants \& Redox Signaling. 22(8):686-729.

[155] McQuaker SJ, Quinlan CL, Caldwell ST, Brand MD, Hartley RC (2013) A Prototypical Small-Molecule Modulator Uncouples Mitochondria in Response to Endogenous Hydrogen Peroxide Production. Chembiochem 14(8):993-1000.

[156] Weissig V, Torchilin VP (2001) Cationic bolasomes with delocalized charge centers as mitochondria-specific DNA delivery systems. Advanced drug delivery reviews 49(1):127149.

[157] Severina II, Vyssokikh MY, Pustovidko AV, Simonyan RA, Rokitskaya TI, Skulachev VP (2007) Effects of lipophilic dications on planar bilayer phospholipid membrane and mitochondria. Biochimica et Biophysica Acta (BBA)-Bioenergetics 1767(9):1164-1168.

[158] Ross M, Da Ros T, Blaikie F, Prime T, Porteous C, Severina I, ... \& Murphy M (2006) Accumulation of lipophilic dications by mitochondria and cells. Biochem J 400:199-208.

[159] Abu-Gosh SE, Kolvazon N, Tirosh B, Ringel I, Yavin E (2009) Multiple triphenylphosphonium cations shuttle a hydrophilic peptide into mitochondria. Molecular pharmaceutics 6(4):1138-1144.

[160] Lehenkari PP, Kellinsalmi M, Näpänkangas JP, Ylitalo KV, Mönkkönen J, Rogers MJ, ... Hassinen IE (2002) Further insight into mechanism of action of clodronate: inhibition of mitochondrial ADP/ATP translocase by a nonhydrolyzable, adenine-containing metabolite. Molecular pharmacology 61(5):1255-1262.

[161] Mönkkönen H, Auriola S, Lehenkari P, Kellinsalmi M, Hassinen IE, Vepsäläinen J, Mönkkönen J (2006) A new endogenous ATP analog (ApppI) inhibits the mitochondrial adenine nucleotide translocase (ANT) and is responsible for the apoptosis induced by nitrogen-containing bisphosphonates. British journal of pharmacology 147(4):437-445.

[162] Murphy MP, Smith RA (2000) Drug delivery to mitochondria: the key to mitochondrial medicine. Advanced drug delivery reviews 41(2):235-250.

[163] Pearson H (2007) Cancer patients opt for unapproved drug. Nature 446(7135):474-475.

[164] Chu QSC, Sangha R, Spratlin J, Vos LJ, Mackey JR, McEwan AJ, ... \& Michelakis ED (2015) A phase I open-labeled, single-arm, dose-escalation, study of dichloroacetate (DCA) in patients with advanced solid tumors. Investigational new drugs:1-8. 
[165] Michelakis ED, Sutendra G, Dromparis P, Webster L, Haromy A, Niven E, ... \& Petruk KC (2010) Metabolic modulation of glioblastoma with dichloroacetate. Science translational medicine 2(31):31ra34-31ra34.

[166] Calcutt NA, Lopez VL, Bautista AD, Mizisin LM, Torres BR, Shroads AL, ... \& Stacpoole PW (2009) Peripheral neuropathy in rats exposed to dichloroacetate. Journal of neuropathology and experimental neurology 68(9):985. 